- Monogràfic -

\title{
EL SECTOR FORESTAL Y LA SALUD: UNA VINCULACIÓN JURÍDICA EN TIEMPOS DEL CAMBIO CLIMÁTICO
}

\section{FORESTRY AND HEALTH: A LEGAL LINKAGE IN TIMES OF CLIMATE CHANGE}

José Miguel García Asensio

Abogado

Doctor en Derecho

urbionak@telefonica.net

Fecha de recepción: 11 de octubre de 2021

Fecha de aceptación: 11 de noviembre de 2021

RESUMEN: En el proceso de producción legislativa en materia de mitigación del cambio climático destacamos, dentro del sector forestal, el uso de típicas técnicas de silvicultura, concretamente las de repoblación forestal, vehiculadas a través de la gestión forestal sostenible, y que han sufrido un lógico proceso de actualización. Además, se detecta una regulación práctica y detallada de la función de sumideros naturales de gases de efecto invernadero de los montes, viéndose obligada la sociedad y el mercado a acudir a sistemas alternativos para alcanzar contraprestaciones económicas a las inversiones que se ejecutan en esos terrenos forestales y a cambio de las externalidades que se generan a favor de la sociedad.

RESUM: En el procés de producció legislativa en matèria de mitigació de l'canvi climàtic destaquem, dins el sector forestal, l'ús de típiques tècniques de silvicultura, concretament les de repoblació forestal, vehiculades a través de la gestió forestal sostenible, i que han patit un lògic procés d'actualització. A més, es detecta una regulació pràctica i detallada de les muntanyes en la seva funció 
d'embornals naturals de gasos d'efecte hivernacle, veient-se obligada la societat i el mercat a acudir a sistemes alternatius per assolir contraprestacions econòmiques a les inversions que s'executen en aquests terrenys forestals ia canvi de les externalitats que es generen a favor de la societat.

ABSTRACT: In the legislative production process on climate change mitigation we highlight, within the forestry sector, the use of typical forestry techniques, specifically those of reforestation, carried through sustainable forest management, and which have suffered a logical upgrade process. In addition, a practical and detailed regulation of the forests is detected in their function of natural sinks of greenhouse gases, being forced the society and the market to resort to alternative systems to achieve economic compensation to the investments that are executed in these forest lands and in exchange for the externalities that are generated in favor of society.

PALABRAS CLAVE: Repoblación forestal - Reforestación - Forestación Silvicultura - Cambio climático - Monte - Bosque - Sumidero - Dióxido de carbono - Gas de efecto invernadero - Restauración - Gestión forestal sostenible - Huella de carbono - Biodiversidad - Salud - Acuerdo de París Soluciones basadas en la Naturaleza - Instrumento de mercado - Objetivos de desarrollo sostenible - Principio "no causar un perjuicio significativo".

PARAULES CLAU: Repoblació forestal - Reforestació - Repoblament Silvicultura - Canvi climàtic - Muntanya - Bosc - Embornal - Diòxid de carboni - Gas d'efecte d'hivernacle - Restauració - Gestió forestal sostenible - Petjada de carboni - Biodiversitat - Salut - Acord de París - Solucions basades en la Naturalesa - Instrument de mercat - Objectius de desenvolupament sostenible - Principi "no causar un perjudici significatiu".

KEYWORDS: Reforestation - Reafforestation - Afforestation - Reforestation Forestry - Climate change - Mountain - Forest - Forest Woodland - Carbon dioxide - Greenhouse gas - Restoration - Sustainable forest management Carbon sink - Biodiversity - Health - Paris Agreement - Nature-based solutions - Market-based solutions - Market-based instruments - Sustainable development objectives - "Do no significant harm" principle. 
SUMARIO: I.- Introducción. II.- Ubicación jurídico-conceptual de la repoblación forestal. III.Relaciones entre las repoblaciones forestales y la salud humana. IV.- La repoblación forestal como instrumento de lucha contra el cambio climático. V.- Una oportunidad perdida: el régimen de cómputo de las absorciones por los sumideros naturales. El caso de la huella de carbono. VI.- El reciente redimensionamiento jurídico de la repoblación forestal. 5.1.- Un nuevo principio para el Derecho Forestal. 5.2.- Desarrollo del principio de restauración. 5.3.- Impulso a la gestión forestal sostenible. 5.4.- La gestión forestal sostenible como un instrumento de lucha contra la pérdida de biodiversidad. VI.- Conclusiones. Bibliografía.

\section{I.- INTRODUCCIÓN}

Una de las líneas más llamativas, y que ha provocado la atención de la más numerosa y cualificada doctrina jurídica en España, como veremos, es la función que desempeñan nuestros montes en la mitigación del cambio climático. Una cuestión que concita unanimidad en otorgarle la mayor de las relevancias en estos tiempos de emergencia climática. Atención que es inversamente proporcional al interés que le presta el legislador, especialmente desde el punto de vista práctico. La silvicultura climática se mueve entre las políticas tradicionales con imposición de nuevas cargas y limitaciones y el reconocimiento de la función de sumidero natural de los montes sin una compensación económica a sus propietarios por una gestión encomiable que produce una serie de externalidades positivas para toda la sociedad.

Este binomio en la lucha contra la deforestación se materializa, primero, en que las tradicionales operaciones de repoblación forestal no sólo se mantienen intactas sino que se reformulan para adaptarse a los nuevos tiempos. $Y$, en segundo lugar, se buscan patrones jurídicos que, ante la ausencia de esa contraprestación a las funciones ambientales de los montes españoles, y entre los pliegues que las normas posibilitan, permiten lograr un cierto reconocimiento como basamento para conseguir algún tipo de rendimiento económico, como es el caso de la huella de carbono.

\section{II.- UBICACIÓN JURÍDICO-CONCEPTUAL DE LA REPOBLACIÓN FORESTAL}


La Ley 43/2003, de 21 de noviembre, de Montes (en adelante, LM), como marco general de la regulación forestal en España, nos aporta una definición legal de repoblación forestal como la introducción de especies forestales en un terreno mediante siembra o plantación ${ }^{1}$. A su vez, esta categoría se desglosa en dos diferentes. La primera es la reforestación, es decir, la reintroducción de especies forestales, mediante siembra o plantación, en terrenos que estuvieron poblados forestalmente hasta épocas recientes, pero que quedaron rasos a causa de talas, incendios, vendavales plagas, enfermedades $u$ otros motivos (apartado h) del art. 6 LM). La otra categoría dentro de la repoblación forestal es la forestación, es decir, la repoblación, mediante siembra o plantación, de un terreno que era agrícola o estaba destinado a otros usos no forestales ${ }^{2}$. Sinónimo de forestación es el término aforestación, actualmente de moda, ausente del Diccionario RAE, y que no es sino un anglicismo procedente del término afforestation ${ }^{3}$.

La mera existencia de esta definición en un texto legal es ya de por sí un avance, por cuanto es la primera ocasión que se detecta en nuestra normativa nacional, quizás debido a que ni siquiera existía unanimidad a la hora de afrontar este concepto desde el punto de vista técnico o silvícola 4 . Al final se ha seguido, a nuestro entender correctamente, el sentido gramatical de "acción de volver a poblar"5, adaptado lógicamente al sector forestal, y siguiendo el parecer de la doctrina jurídica más tradicional ${ }^{6}$.

La dicotomía entre reforestación y forestación ya venía siendo apuntada, en el plano jurídico, por alguna doctrina ${ }^{7}$, para quien la primera respondería a fines

\footnotetext{
${ }^{1}$ Apartado f) del art. 6 (LM).

${ }^{2}$ Apartado g) del art. 6 (LM).

${ }^{3}$ MEDINA (1988: 36).

${ }^{4}$ PIZARRO NEVADO (2000: 143).

${ }^{5}$ RAE (1992: 1774).

${ }^{6}$ Es el caso de MASA ORTIZ (1964: 357), quien entendía por repoblación el conjunto o serie de actos por virtud del cual va a ser poblado, artificialmente y con la intervención de la mano del hombre y por cualquiera de los medios que impone la técnica forestal, un terreno con especies arbóreas, independientemente de que dicho terreno hubiera estado o no anteriormente dedicado al cultivo forestal. ${ }^{7}$ PIZARRO NEVADO (2000: 145 y 146), a quien seguiremos en esta cuestión. Este autor recuerda que ya en el Simposio Mundial sobre Repoblación Forestal, celebrado en Camberra en 1967, se diferenció conceptualmente entre forestación o repoblación forestal, que sería el establecimiento artificial de bosques en terrenos que previamente, dentro del periodo de 50 años (que correspondería con la memoria de una generación), no sostenían bosques; reforestación, que es el establecimiento artificial de bosques en terrenos que previamente sostenían bosques y supone el reemplazamiento de la masa previa por una nueva; regeneración artificial, que es el establecimiento de bosques en tierras que previamente sostenían bosques y supone el establecimiento esencial de la misma producción que existía anteriormente; y,
} 
que podríamos llamar "clásicos", es decir, de producción, protección de cuencas, del medio, de restauración del espacio forestal, etc.... La segunda, en cambio, junto a la anterior, puede perseguir otros fines, como el abandono de tierras de cultivo o el aumento de la superficie forestal. Como quiera que el concepto legal de monte abarca también los terrenos destinados a ser transformados en forestales ${ }^{8}$, tanto reforestación como forestación van tan estrechamente unidos que conforman e integran la categoría jurídica de repoblación forestal. Así mismo, y como fuente directa de la previsión en la LM, es el Plan Forestal Español de 2002, en cuyo Apartado 1.4 se distingue entre la reforestación como "restauración de sistemas forestales en los terrenos que han sido tradicionalmente dedicados a este uso" y la forestación como "instauración de bosques en terrenos agrícolas abandonados o sin uso definido".

Como ya hemos dejado dicho en anteriores ocasiones ${ }^{9}$, aunque tanto reforestación como forestación coinciden en ser repoblaciones forestales al introducir especies forestales ${ }^{10}$ en un terreno mediante siembra o plantación se distinguen en que la segunda se produce en terrenos no forestales, mientras que la primera tiene lugar en montes objeto de aprovechamiento en orden a restaurar su cubierta arbórea. Reforestar se produce en terrenos con la condición de monte, mientras que la forestación viene a ser la operación por la que los terrenos que tienen el designio de ser forestales alcanzan plenamente dicha condición. En definitiva, al forestar se crea el bosque, y al reforestar se prolonga su existencia por mera continuidad tras una corta o un incendio ${ }^{11}$. Forestar responde al principio de fomento forestal, creando nueva superficie de esta naturaleza, mientras que reforestar se ubica dentro del ámbito de

finalmente, regeneración natural, que entiende el conjunto de acciones encaminadas a ayudar a la regeneración de las especies forestales ya existentes en el monte (pág. 144).

${ }^{8}$ Art. 5.1.d) (LM) determina que también tiene la condición legal de monte aquel terreno que, sin reunir las características propias de monte, se adscriba a la finalidad de ser repoblado o transformado al uso forestal.

${ }^{9}$ GARCÍA ASENSIO (2018.a: 132 y 133).

${ }^{10}$ Apartado f) del art. 6 (LM) y art. 8.29 (Ley 7/2012, de 28 de junio, de montes de Galicia, en adelante, LMG).

${ }^{11}$ Antes del nacimiento de la Ciencia Forestal en el siglo XIX, se utilizaban técnicas propias de la Arboricultura en la reforestación, como bien la describe GARCÍA MARTINO (1868: 523 y 524): “ $L a$ necesidad de replantar los montes y la de asegurar el repoblado después de las cortas, obligó á que los cultivos, siembras y plantaciones se aplicasen, mandándose entre otras cosas que los vecinos de los pueblos plantasen un cierto número de árboles por cada uno que cortasen. Pero esta primera medida era todavía muy local y nunca dio buenos resultados (...)". 
actuación del principio constitucional de restauración (art. 45.2 CE). Y aunque ambas han sido técnicas al servicio de la producción de maderas, lo cierto es que actualmente se enmarcan dentro de la protección ambiental ${ }^{12}$.

La doctrina jurisprudencial ha intuido una diferencia conceptual, aunque concretando lo reflejado en la $\mathrm{LM}^{13}$. Así, la STS de 20 de julio de 2006, Sala de lo Contencioso-Administrativo, rec. núm. 7059/2000, Ar. 6024, Ponente: Excmo. Sr. D. Mariano Baena del Alcázar, F.J. 1ํㅜ distingue entre la reforestación, como obligación esencial de la Administración forestal, y la conservación, como obligación general de la misma. En todo caso, estamos ante actividades que constituyen una forma de mejora del monte, es decir, que tienden al fomento de la producción forestal, como ha señalado nuestra doctrina tradicional más autorizada ${ }^{14}$.

Estas cuestiones aparecen más claras en las definiciones aportadas por la Decisión 16/CMP.1 "Uso de la tierra, cambio de uso de la tierra y silvicultura" adoptada en Montreal de 2005, al entender por forestación la "conversión, por actividad humana directa, de tierras que carecieron de bosque durante un periodo mínimo de 50 años en tierras forestales mediante plantación, siembra o fomento antropógeno de semilleros naturales", y por reforestación la "conversión por actividad humana directa de tierras no boscosas en tierras forestales mediante plantación, siembra o fomento antropógeno de semilleros naturales en terrenos donde antiguamente hubo bosques, pero que están actualmente deforestados ${ }^{15}$. En el primer periodo de compromiso, las actividades de reforestación se limitarán a la reforestación de terrenos carentes de bosques al 31 de diciembre de 1989". Visto lo cual surgen algunas cuestiones a resolver. Primeramente, que en la práctica la distinción entre estos dos conceptos reside en el tiempo que el terreno ha estado sin cubierta vegetal: si supera los 50 años es forestación (nos permitimos recordar

\footnotetext{
${ }^{12}$ LÓPEZ RAMÓN (2002: 72 y 73).

${ }^{13}$ Los aspectos de la política forestal son dinámicos pues “(...) no es un conjunto de principios fijados de una vez para siempre, sino que evoluciona y se modifica bajo el influjo de motivaciones diversas en relación con las tres utilidades de los montes correspondientes a sus funciones protectora, productora y ambiental" (OYARZUN LARRAYOZ 1975: 14).

${ }^{14}$ GUAITA (1986: 260). En el mismo sentido PIZARRO NEVADO (2000: 145) en base al texto del antiguo art. 33 (LM-1957) en su inciso final, cuando admite que las repoblaciones forestales son una forma de mejora forestal.

${ }^{15}$ La misma Directiva concibe la deforestación como la "conversión por actividad humana directa de tierras boscosas en tierras no forestales" (apartado 1.d) del Anexo).
} 
nuevamente que este lapso temporal se fija por considerarlo correspondiente a la memoria de una generación) y, en caso contrario, es reforestación, aunque las actividades que fueron amparadas por el Protocolo de Kyoto (art. 3.3) se referían sólo a las tierras sin esa cubierta antes de 1989, lo que suponía un problema de prueba sobre todo en países no desarrollados ${ }^{16}$. La segunda, es la no coincidencia de estas definiciones con las ya expuestas de la LM, pues aunque en esencia delimitan el mismo concepto, no son coincidentes. La solución, más que por una modificación de la LM para acoger el texto de la Decisión, debe venir por una interpretación conjunta e integradora pues, no conviene olvidarlo, la Decisión sólo tiene el alcance en el campo del cambio climático, mientras que la LM es más general y amplia, llegando a ámbitos ajenos al de la Decisión. Y esta normativa climática sólo hace referencia a los bosques, conceptualmente diferentes de nuestros montes ${ }^{17}$, siendo éste mucho más adecuado por cuanto es comprensivo de nuestras peculiaridades naturales, especialmente las mediterráneas.

En todo caso, la forestación ha tenido un reconocimiento comunitario en cuanto instrumento para el aumento de la superficie forestal en Europa en las últimas décadas a través de la Nueva Estrategia Forestal de la UE para $2030^{18}$. También, de modo más indirecto, en el Reglamento (UE) 2018/841, del Parlamento Europeo y del Consejo, de 30 de mayo de 2018, sobre la inclusión de las emisiones y absorciones de gases de efecto invernadero resultantes del uso de la tierra, el cambio de uso de la tierra y la silvicultura en el marco de actuación en materia de clima y energía hasta 2030, y por el que se modifican el Reglamento (UE) núm. 525/2013 y la Decisión núm. 529/2013/UE (en

\footnotetext{
${ }^{16}$ DESANKER (2005: 25).

${ }^{17}$ La diferencia entre monte y bosque ya la hemos tratado con mayor amplitud en GARCÍA ASENSIO (2017: 49 a 56) y GARCÍA ASENSIO (2018.a: 121 y 122). Más recientemente GARCÍA LOZANO (2021: 234 y ss.). Debe tenerse siempre presente que el concepto de monte es mucho más amplio que el de bosque y responde a la realidad propia de nuestro país, con una vegetación de influencia mediterránea, y por lo tanto con una silvicultura diferente a la continental europea. Por eso, por especie forestal debemos entender toda especie arbórea, arbustiva, de matorral o herbácea que no es característica de forma exclusiva del cultivo agrícola (art. 6.b) LM), mientras que el concepto de bosque repugna toda especie que no sea arbórea.

${ }^{18}$ Comunicación de la Comisión al Parlamento Europeo, al Consejo, al Comité Económico y Social Europeo y al Comité de las Regiones Vacías (COM (2021) 572 final), Introducción, tercer párrafo.
} 
adelante, Reglamento UTCUTS ${ }^{19}$ ), cuando se habla de tierras forestadas como aquellas que han sido "convertidas en tierras forestales" (art. 2.1.a).i)).

A su vez, las normativas autonómicas han introducido otros conceptos que se fundamentan en meros matices sobre lo ya expuesto. Es el caso del art. 8.31 (LMG), que encaja en un texto normativo la noción de regeneración forestal: "renovación de una masa arbolada por procedimientos naturales o artificiales". Es decir, es una operación dentro de la reforestación, pues al tratarse de una "renovación" es obvio que se parte de un bosque preexistente y no de nueva implantación. Pero, como puede apreciarse, no deja de ser una mera puntualización de los términos analizados.

Estas diferenciaciones conceptuales tienen su trascendencia más allá de una discusión doctrinal y terminológica. Así, a efectos de la contabilidad climática y posibles compensaciones por emisiones de gases de efecto invernadero no es lo mismo una forestación que una reforestación pues las actividades amparadas por el proceso de la Convención Marco de las Naciones Unidas sobre el Cambio Climático (en adelante, CMNUC) se refieren sólo a las tierras sin cubierta forestal antes de $1989^{20}$, por lo que los bosques existentes en esa fecha y muchas reforestaciones no serán consideradas a estos efectos.

\section{III.- RELACIONES ENTRE LAS REPOBLACIONES FORESTALES Y LA SALUD HUMANA}

La vinculación entre repoblación forestal y la salud humana está muy presente en nuestro ordenamiento positivo, especialmente cuando se trata de mitigar el cambio climático. De entre los ejemplos más recientes destacamos, en primer lugar, la Resolución de la Asamblea General de la ONU 73/284, de 1 de marzo de 2019, sobre "Decenio de las Naciones Unidas sobre la Restauración de los Ecosistemas (2021-2030)", en cuya parte expositiva pone de relieve que los bosques son esenciales para, entre otros aspectos, la mejora del bienestar de los seres humanos. Dentro del Derecho nacional, y a los efectos del presente estudio, el paradigma es el art. 2 de la Ley $7 / 2021$, de 20 de mayo, de cambio

\footnotetext{
${ }^{19}$ Estas actividades también son conocidas como LULUCF por sus siglas en inglés: Land Use, Land Use Conservation anf Forest (RODRÍGUEZ-CHAVES MIMBRERO 2018: 622).

${ }^{20}$ DESANKER (2005: 25).
} 
climático y transición energética (en adelante, LCC) ${ }^{21}$. Así, la ejecución de los objetivos del Acuerdo de París de 2015 se rige en nuestro Derecho nacional por una serie de principios rectores, entre los que se encuentran la "Protección del medio ambiente" (apartado c) del art. 2 LCC) junto a la "Protección y promoción de la salud pública" (apartado f) del art. 2 LCC). Estos principios, junto al resto de los que se relacionan en este precepto, no son compartimentos estancos sino que deben ser entendidos y aplicados de forma imbricada entre ellos para su correcta inteligencia ${ }^{22}$. Al fin y al cabo el Mecanismo de Recuperación y Resiliencia (en adelante, MRR) se apoya en seis pilares, siendo la transición ecológica y la salud dos de ellos ${ }^{23}$, todo ello en cumplimiento del objetivo de neutralidad climática de la UE para 205024. De ahí que un sistema alimentario justo y saludable ineluctablemente debe conducir a la utilización de prácticas sostenibles, como la agrosilvicultura, como pone de manifiesto el denominado Pacto Verde Europeo ${ }^{25}$.

Esta vinculación, reiterada en el art. 23.1 (LCC) cuando prescribe el fomento de la mejora del conocimiento sobre los efectos del cambio climático en la salud pública y sobre las iniciativas encaminadas a su prevención, no es baladí por cuanto actualmente el concepto salud se ha ido ampliando hasta albergar un marco de procesos multicausales que determinan la salud humana en su conjunto. Más allá de factores genéticos heredados o accidentes sufridos, nuestro estado de salud también es resultado de nuestro comportamiento, lugar donde vivimos, ingresos económicos, nivel de educación, acceso a la atención sanitaria y, sobre todo en lo que ahora nos atañe, las características

\footnotetext{
${ }^{21}$ Una ley específica sobre el cambio climático ya fue reclamada hace tiempo por SARASÍBAR IRIARTE (2007: 178), por lo que la LCC, aunque tardíamente, da cumplimiento a esta preclara propuesta.

${ }^{22}$ De hecho, esta integración de las previsiones climáticas en la planificación y gestión de políticas sectoriales viene reconocida en el apartado IV de la propia E. de M. de la LCC.

${ }^{23}$ Art. 9 del Reglamento (UE) 2020/852, del Parlamento y del Consejo, de 18 de junio, relativo al establecimiento de un marco para facilitar las inversiones sostenibles y por el que se modifica el Reglamento (UE) 2019/2088, que los relaciona: a) mitigación del cambio climático; b) adaptación al cambio climático; c) uso sostenible y protección de los recursos hídricos y marinos; d) transición hacia una economía circular; e) prevención y control de la contaminación; y f) protección y recuperación de la biodiversidad y los ecosistemas. Reiterados en el art. 3 del reciente Reglamento (UE) 2021/241 del Parlamento Europeo y del Consejo, de 12 de febrero de 2021, por el que se establece el Mecanismo de Recuperación y Resiliencia (en adelante, Reglamento del MRR).

${ }^{24}$ Art. 4.1 (Reglamento del MRR).

${ }^{25}$ Comunicación de la Comisión al Parlamento Europeo, al Consejo Europeo, al Consejo, al Consejo Económico y Social Europeo y al Comité de las Regiones (COM (2019) 640 final, de 11 de diciembre de 2019), Apartado 2.1.6.
} 
del Medio Ambiente que nos rodea ${ }^{26}$. Y, al igual que los principios expresados, esos ámbitos no son esferas independientes y estancas, pues nuestro comportamiento modifica el medio, con la deforestación ${ }^{27}$ y, por lo tanto, la reforestación como paradigmas.

Además, no sólo la repoblación forestal beneficia la salud sino que también se produce una relación en sentido inverso, pues la atención médica reduce la deforestación. Una mejora de la atención médica en zonas rurales resulta efectiva para reducir la tala ilegal de los bosques, por cuanto el aumento de la calidad de vida de sus habitantes repercute positivamente en el Medio Ambiente ${ }^{28}$.

Otros ejemplos de la citada imbricación en nuestros textos normativos nos aparece, primeramente, en el reciente Reglamento (UE) 2021/1119, del Parlamento Europeo y del Consejo de 30 de junio de 2021 por el que se establece el marco para lograr la neutralidad climática y se modifican los Reglamentos (CE) núm. 401/2009 y (UE) 2018/1999, en cuya parte expositiva reconoce que la mejora de las capacidades de adaptación y de la resiliencia contribuye a mejorar las condiciones de vida en las zonas afectadas: "Prepararse con suficiente tiempo a dichas consecuencias es eficiente en términos de costes y también puede reportar considerables beneficios colaterales para los ecosistemas, la salud y la economía" (Considerando $32^{\circ}$ ). Además, en el Anexo III de la Comunicación de la Comisión (2021/C 58/01) "Guía técnica sobre la aplicación del principio de "no causar un perjuicio significativo» en virtud del Reglamento relativo al Mecanismo de Recuperación y Resiliencia" (en adelante, Guía técnica), se fija como condición específica

\footnotetext{
${ }^{26}$ PAHISSA ESPLUGA (2021: 77).

${ }^{27}$ PAHISSA ESPLUGA (2021: 78), quien pone de relieve que las zonas verdes, entre otros beneficios, hace disminuir las tasas de morbilidad y mortalidad, contribuye a reducir el sobrepeso y la obesidad, también las probabilidades de sufrir enfermedades coronarias, cardiacas, ictus, hemorragias cerebrales y el síndrome metabólico, contribuye a la salud mental, y refuerza el sistema inmunitario: la inhalación de monoterpenos de atmósferas forestales se ha asociado con la estimulación de este sistema (PAHISSA ESPLUGA 2021: 79-81).

${ }^{28}$ VIEITES y HERRANDO-PÉREZ (2021: 54 y 55), quienes explican el concreto caso de las comunidades cercanas al Parque Nacional de Gunung Palung, en Borneo (Indonesia): en 2007 se estableció una clínica en la zona con el incentivo de aplicar descuentos para los usuarios que abandonaran la tala ilegal de árboles dentro del área protegida. Tras diez años la deforestación ilegal se redujo en un 70 por 100, a la par que ha disminuido la incidencia de la malaria y la tuberculosis, así como varias enfermedades infantiles y pulmonares.
} 
para el cumplimiento del objetivo de mitigación del cambio climático ${ }^{29}$ del principio "no causar un perjuicio significativo", del que luego hablaremos más detenidamente, en el marco del plan de recuperación y resiliencia, el dar "lugar a una mejora significativa del medio ambiente (especialmente debido a la reducción de la contaminación) y la salud pública (...)"30.

\section{IV.- LA REPOBLACIÓN FORESTAL COMO INSTRUMENTO DE LUCHA CONTRA EL CAMBIO CLIMÁTICO}

A estas alturas resulta obvio recordar que los montes son un sumidero natural por cuanto realizan el triple papel de capturar, almacenar y sustituir el carbono atmosférico ${ }^{31}$, algo que ya fue reconocido en su momento por el Protocolo de Kyoto $^{32}$, por el Plan Forestal Español de 2020 (Apartado 2.4) y por el art. 65.2.b) (LM): "La fijación de dióxido de carbono en los montes como medida de contribución a la mitigación del cambio climático, en función de la cantidad de carbono fijada en la biomasa forestal del monte (...)", aunque no emplee el término sumidero. A efectos de concretar el debate, es preciso recordar que por sumidero debe entenderse el proceso por el que se sustrae un gas o gases de la atmósfera ${ }^{33}$. Y tendrán la condición de biológicos "los formados por biomasa viva como depósito de $\mathrm{CO}$, excluyendo de la contabilización la

\footnotetext{
${ }^{29}$ Entendiendo por tal, ex. apartado t) del art. 4 de la Ley 10/2019, de 22 de febrero, de cambio climático y transición energética de las Islas Baleares, "el conjunto de objetivos, planes y acciones de cualquier tipo tendentes a reducir el impacto que la actividad humana tiene sobre la alteración del sistema climático global. Su ámbito principal de acción es la reducción de la emisión de gases de efecto invernadero teniendo en cuenta, también, otros ámbitos de acción, como la alimentación, la planificación del transporte, la agricultura, la ganadería, la pesca, la reforestación o la conservación de espacios naturales que son almacenes o sumideros de carbono".

${ }^{30}$ En concreto en áreas donde se sobrepasan las normas de calidad del aire de la Unión Europea establecidas por la Directiva 2008/50/UE o se corre el riesgo de sobrepasarlas, como cuando se sustituyen sistemas de calefacción y calderas a base de carbón o petróleo.

${ }^{31}$ Considerando $23^{\circ}$ del Reglamento (UE) 2021/1119.

${ }^{32}$ SARASÍBAR IRIARTE (2007: 121-136).

${ }^{33}$ Plan Estratégico del Patrimonio Natural y la Biodiversidad 2011-2017. En parecidos términos se expresa el art. 3.1.1 del Reglamento UTCUTS así como el apartado i) del art. 2 del Decreto 40/2021, de 29 de julio, por el que se regula la organización y funcionamiento del registro de huella de carbono para la reducción, absorción y compensación de emisiones de gases de efecto invernadero del Principado de Asturias: "todo sistema o proceso por el que se extrae de la atmósfera un gas o gases de efecto invernadero y se almacena. Se trata de actividades de uso de la tierra, cambio de uso de la tierra y selvicultura: actividades de forestación y reforestación; gestión de tierras agrícolas; gestión de bosques; gestión de pastos y restablecimiento de la vegetación", resultando interesante su vinculación al sector UTCUTS, pues implica una referencia únicamente a los sumideros naturales o biológicos, excluyéndose por tanto los geológicos.
} 
materia orgánica muerta" 34 . Por tanto, es obvio que los montes se encuadran dentro de esta categoría. La Ley 16/2017, de 1 de agosto, del cambio climático, de Cataluña ${ }^{35}$, reserva exclusivamente la condición de sumidero a aquellos reservorios que absorben o almacenan carbono "como parte del ciclo natural del carbono" (art. 4.f)), lo que supone que expulsa de esta condición a los sumideros geológicos, ya que no participan de ese ciclo natural.

No obstante, esta idea de los montes como sumideros subyace en más preceptos de la LM, pues el art. 3.g) de esta Ley consagra como principio que inspira dicho texto legal "La integración en la política forestal española de los objetivos de la acción internacional sobre protección del medio ambiente, especialmente en materia de desertificación, cambio climático y biodiversidad", reforzado posteriormente con la adición de un nuevo apartado k) al aludido precepto, operada por Ley 10/2006, de 28 de abril, y referida al principio de "Adaptación de los montes al Cambio Climático, fomentando una gestión encaminada a la resiliencia y resistencia de los montes al mismo", y enlazado con el declarado servicio ambiental que los montes proveen de "fijación del carbono atmosférico" (art. 4 LM) ${ }^{36}$. Que el legislador consideraba expresamente a nuestros montes como un sumidero de carbono nos lo confirma el dato de que en el debate plenario de la LM se señaló que "los bosques no solamente nos pueden servir para favorecer una menor emisión de gases de efecto invernadero y hacer el efecto sumidero, como normalmente se denomina, sino que además tienen que salvaguardar la biodiversidad"37. Sin mencionarlos también los considera como "sumideros vinculados al uso forestal sostenible" el art. 89.2 (Ley 2/2011, de 4 de marzo, de Economía Sostenible), reconociendo la producción de externalidades positivas a fomentar.

También algunas normas autonómicas asumen en sus respectivos textos forestales la función de sumidero que les corresponde a los montes. Por ejemplo, la Ley 5/1994, de 16 de mayo, sobre fomento de los montes arbolados

\footnotetext{
${ }^{34}$ Art. 1.2.c) del Real Decreto 163/2014, de 14 de marzo, de 14 de marzo, por el que se crea el registro de huella de carbono, compensación y proyectos de absorción de dióxido de carbono.

${ }^{35}$ Recordemos que Cataluña es la Comunidad Autónoma pionera en aprobar una completa regulación de medidas de mitigación y de adaptación (LÓPEZ RAMÓN 2021: 3).

${ }^{36}$ De aquí SARASÍBAR IRIARTE (2007: 173 y 174) infiere acertadamente y sin género de dudas que uno de los principios inspiradores de la LM es la función de sumidero de nuestros bosques.

${ }^{37}$ Boletín Oficial de las Cortes Generales. Congreso de loa Diputados núm. 275, de 11 de septiembre de 2003 (SARASÍBAR IRIARTE 2007: 176).
} 
en Castilla y León, aunque sin utilizar ese término ${ }^{38}$; el art. 87.2.b) de la Ley 3/2004, de 23 de noviembre, de montes y ordenación forestal de Asturias, con idéntica redacción que el citado art. 65.2.b) (LM), al igual que el art. 78.2.b) de la Ley 3/2008, de 12 de junio, de Montes y Gestión Forestal Sostenible de Castilla-La Mancha; la Ley 7/2012, de 28 de junio, de Montes de Galicia dedica su Disposición Adicional Tercera a este tema, con un expresivo rótulo: "De los bosques como sumideros de carbono"; la Ley 3/2009, de 6 de abril, de montes de Castilla y León sólo habla expresamente de los montes como sumidero en su E. de M. ${ }^{39}$; y la catalana Ley 16/2017 califica a los bosques como uno de los sumideros más comunes (art. 4.f)).

El principal punto de inflexión a este respecto ha sido el Acuerdo de París de 2015, que también reconoce esta función al incluir expresamente a los bosques entre los sumideros (art. 5.1), lo que ya supuso un avance, pues el Protocolo de Kyoto carecía de este reconocimiento expreso. Hasta tal punto que hasta hace poco en el Derecho aplicable en España prácticamente no han sido objeto de regulación normativa ${ }^{40}$, suponiendo este tratado internacional un punto de inflexión. Incluso desde la ONU se ha efectuado este reconocimiento expreso, al recordar que los sumideros de gases de efecto invernadero incluyen los bosques, a través de la ya referenciada Resolución 73/284, de 1 de marzo de 2019.

De aquí el importante Reglamento (UE) 2021/1119, del Parlamento Europeo y del Consejo, ya calendado, que viene a ser la Ley del Clima Europea ${ }^{41}$, al

\footnotetext{
${ }^{38} \mathrm{En}$ su E. de M. se puede leer lo siguiente: "Por último, son un paliativo eficaz, aunque parcial, contra la contaminación atmosférica por dióxido de carbono y, por tanto, uno de los pocos recursos efectivos que la humanidad de hoy tiene para alejar, en lo posible, el llamado «efecto invernadero»".

39 "La sociedad actual percibe los montes como sistemas complejos que, si bien están llamados a seguir produciendo bienes directos a sus propietarios con destino al consumo, deben satisfacer una creciente demanda de servicios indirectos al conjunto de la sociedad, como la tradicional protección hidrológica pero también de otros conceptos más novedosos como la conservación de la biodiversidad o del paisaje, el efecto sumidero de anhídrido carbónico (...)".

${ }^{40}$ Más que regulatorias, alguna Administración ha dictado disposiciones aisladas conteniendo medidas concretas, como el Acuerdo 26/2020, de 4 de junio, de la Junta de Castilla y León, por el que se aprueban medidas contra el cambio climático en el ámbito de la Comunidad de Castilla y León, como la de poner en marcha un Plan de Acción Forestal por el Cambio Climático de Castilla y León, “(...) en colaboración con los propietarios y productores forestales, para adaptar nuestros bosques a los retos planteados y prevenir incendios forestales y otros daños, incrementando, además el uso de madera y otros recursos forestales, en sustitución de productos más contaminantes, especialmente en la construcción. En el marco de este Plan, se prevé la plantación de 15.000 nuevas hectáreas de bosque con más de 20 millones de árboles" (Medida $8^{a}$ de su Anexo), además de considerar a la biomasa como combustible de referencia $\left(\right.$ Medida $3^{\mathrm{a}}$ ).

${ }^{41}$ SORO MATEO (2020: 285) y LÓPEZ RAMÓN (2021: 3).
} 
hablar en su parte expositiva que "(...) las soluciones basadas en la naturaleza pueden ser beneficiosas para la mitigación del cambio climático, la adaptación a éste, y la protección de la biodiversidad" (Considerando $32^{\circ}$ ). Aunque el término no aparece como tal en el texto articulado, lo cierto es que esta cita a las "soluciones basadas en la naturaleza" se trata de una novedad muy interesante y que es necesario celebrar, especialmente en el marco de la lucha contra el cambio climático.

Nos explicamos. Como bien se sabe, dentro del ámbito de la captura, uso y almacenamiento del carbono existen dos tipos de medidas ${ }^{42}$. La primera engloba las soluciones de naturaleza tecnológica, centradas en capturar el carbono emitido en entornos industriales a través de muy diversas técnicas o bien captándolo directamente del aire, siendo su principal exponente legislativo en España la Ley 40/2010, de 29 de diciembre, de almacenamiento geológico de dióxido de carbono. La segunda, en cambio, agrupa las soluciones basadas en la Naturaleza $(\mathrm{SbN})$, que son aquéllas que contribuyen a la reducción de las emisiones de carbono a la atmósfera mediante la mitigación, el secuestro y el almacenamiento de carbono en entornos naturales como bosques, humedales, turberas, marismas y lechos marinos. Como puede verse, la repoblación forestal es una medida encuadrable dentro de este segundo grupo, caracterizado por que si bien tienen un coeficiente relativamente bajo en cuanto a su potencial de captación de dióxido de carbono, presentan un menor coste que el resto de medidas de secuestro de carbono ${ }^{43}$.

No debe perderse de vista que las $\mathrm{SbN}$ se conciben, en definición de la Unión Internacional para la Conservación de la Naturaleza (UICN), como "acciones dirigidas a proteger, gestionar y restaurar de manera sostenible ecosistemas naturales o modificados, que hacen frente a retos de la sociedad de forma efectiva y adaptable, proporcionando simultáneamente bienestar humano y beneficios de la biodiversidad"44. Como puede apreciarse todo proyecto de repoblación forestal es una acción que toma en consideración los dos pilares básicos de SbN: por un lado, proporciona beneficios para la biodiversidad

\footnotetext{
${ }^{42}$ Respecto a esta distinción seguimos a ARAUZ y MARZO (2021: 24-31).

${ }^{43}$ ARAUZ y MARZO (2021: 27).

${ }^{44}$ WCC-2016-Res-069-EN "Defining Nature-based Solutions", disponible en https://www.iucn.org/sites/dev/files/content/documents/wcc_2016_res_069_en.pdf.
} 
porque restaura el medio forestal, a la par que, como hemos visto, supone un aporte a favor de la salud pública, y, por otro, al constituir un sumidero de carbono implica colaborar en el reto social de la lucha contra el cambio climático ${ }^{45}$.

Esta importancia en la mitigación del cambio climático, a través de la captura del dióxido de carbono atmosférico como $\mathrm{SbN}$, tiene su reflejo en la normativa climática: para alcanzar el objetivo climático vinculante de la Unión Europea para 2030 consistente en una reducción interna de las emisiones netas de gases de efecto invernadero (emisiones una vez deducidas las absorciones) de, al menos, un 55 por 100 con respecto a los niveles de 1990, de aquí a 2030, conforme el art. 4.1 (Reglamento (UE) 2021/1119), así como el de neutralidad climática, es decir, que las emisiones y absorciones de esos gases regulados en el Derecho de la Unión Europea han de estar equilibrados internamente ${ }^{46}$ a más tardar en 2050 , por lo que en esa fecha las emisiones netas deben haberse reducido a cero y, a partir de entonces, la Unión tendrá como objetivo lograr unas emisiones netas (art. 2.1 Reglamento (UE) 2021/1119), las instituciones competentes de la UE y de sus Estados miembros deberán dar prioridad al aumento de la absorción por parte de los sumideros naturales. Así, la Nueva Estrategia Forestal de la UE para 2030, Introducción, quinto párrafo, $y$, en similares términos, el tan citado Reglamento (UE) 2021/1119, art. 4.1 segundo párrafo ${ }^{47}$.

De este modo, la LCC a lo largo de su articulado instituye una serie de medidas en el sector forestal, partiendo de una genérica inclusión de la política forestal dentro del desarrollo rural a modo de basamento para las mismas, con medidas encaminadas a reducir la vulnerabilidad al cambio climático "de los montes y de los suelos forestales" ${ }^{\prime 4}$. Esta cita genérica se compadece mal con la que parece ser la voluntad del legislador, pues en su E. de M. (Apartado IV) se

\footnotetext{
${ }^{45}$ Que la repoblación forestal es un instrumento de lucha contra el cambio climático nos lo recuerdan ESPINEL GONZÁLEZ y ORTEGA SÁNCHEZ (2021: 176-177), para lo que apuntan a las nuevas tecnologías como herramientas adecuadas para llevarla a efecto.

${ }^{46}$ En palabras de LÓPEZ RAMÓN (2021: 4), que los gases de efecto invernadero emitidos a la atmósfera quedan compensados con los capturados en los bosques y otros sumideros.

${ }^{47}$ Lógicamente, esta prioridad se comparte con la de reducción de emisiones.

${ }^{48}$ Primer párrafo de su art. 25. Entendemos que esta cita conjunta a los montes y a los suelos forestales es una reiteración innecesaria, pues existe plena identidad entre ambos términos, y que encaja íntegramente en la crítica que se le formula a la LCC de ser un texto "retórico y redundante" (LÓPEZ RAMÓN 2021: 20).
} 
explicita que la política forestal se considera clave para alcanzar el objetivo de neutralidad climática.

Así, en primer lugar, se contemplan actuaciones de estudio que permitan planificar futuras medidas. Es el caso de la elaboración de un mapa de vulnerabilidad, que deberá incorporarse en la aplicación de la Política Agraria Común, así como en otras estrategias, planes y programas en materia de política agraria y de desarrollo rural, además de, por supuesto, el Plan Forestal Español ${ }^{49}$. A las que es preciso añadir la identificación, clasificación y cartografía de los sumideros de carbono, así como su evaluación y contabilización a partir de las fuentes de información existentes ${ }^{50}$, lo que en el caso de los montes se nos antoja una labor ímproba.

En general, todo estudio de riesgos es la solución para garantizar un planeamiento resiliente ${ }^{51}$. De ahí que estas labores previas son importantes en el caso de la reforestación, por cuanto, la identificación de una masa forestal como sumidero obliga, en caso de su legítimo aprovechamiento, a su debida reforestación. Ninguna norma legal lo establece así expresamente, pero uno de los principios rectores asumidos en la LCC es el de no regresión ${ }^{52}$, que en el caso de los montes adquiere una gran importancia, además de por lo ya expuesto, porque los proyectos forestales se caracterizan por su fácil reversibilidad, bien por la deforestación causada por el hombre, bien por el impulso del ciclo económico, sin olvidar plagas, enfermedades, desastres naturales, incendios ${ }^{53} \ldots$, lo que obliga a incidir en su conservación y mantenimiento.

Aparte se contemplan actuaciones de planificación, como es la inclusión en la Estrategia de Transición Justa contenidos de políticas forestales (art. 27.2.c) LCC). Esta Estrategia constituye el instrumento de ámbito estatal dirigido a la optimización de las oportunidades en la actividad y el empleo de la transición

\footnotetext{
${ }^{49}$ Primer párrafo del art. 25 (LCC).

${ }^{50}$ Art. 26.1 (LCC).

${ }^{51}$ AGUIRRE I FONT (2019: 6).

${ }^{52}$ LÓPEZ RAMÓN (2021: 8), en base a que el art. 3 (LCC) sólo permite la revisión al alza de los objetivos mínimos nacionales. No debe perderse de vista la importancia de este principio, por cuanto "Es una derivación del principio de desarrollo sostenible, que impone un progreso solidario con las generaciones futuras, solidaridad que implica no retroceder nunca en las medidas de protección del medio ambiente" (LÓPEZ RAMÓN 2011: 21). JAQUENOD DE SZöGöN (1991: 371 y ss.) no lo cita expresamente, pero puede entenderse implícito en el principio de regulación jurídica integral.

${ }^{53}$ RODRÍGUEZ ÁLVAREZ (2017: 3 y 9).
} 
hacia una economía baja en emisiones de gases de efecto invernadero y a la identificación y adopción de medidas que garanticen un tratamiento equitativo y solidario a las personas trabajadoras y territorios en dicha transición (art. 27.1 LCC).

También se recogen otro tipo de medidas, esta vez de fomento. Ciertamente algunas de ellas son un tanto genéricas, necesitadas de la debida concreción ${ }^{54}$, pero que pueden servir de base para futuros acuerdos. Por ello se echa en falta, al menos, la determinación de su destinatario, ausencia que limita el alcance de las medidas y abunda en esta concepción un tanto voluntarista que la aleja de una dimensión práctica y, en consecuencia, de su deseable eficacia, al fin y al cabo objetivo último de toda norma. En todo caso, y como el resto de previsiones de este tipo, se encuentran dispersas en el texto de la $\mathrm{LCC}^{55}$, por lo que las iremos sistematizando tras su localización.

Primeramente recoge la promoción de "(...) prácticas de gestión forestal sostenibles para aumentar su resiliencia frente al cambio climático, que fomentarán en todo caso las sinergias con la reducción de emisiones de gases de efecto invernadero en estos ecosistemas" (primer párrafo del art. 25 LCC). Estas prácticas enlazan con los instrumentos de mercado certificadores, pues son el medio para acreditar la gestión forestal sostenible de un bosque ${ }^{56}$.

En lógica correlación con el espíritu de la LCC, se contempla otra medida de fomento, como es el aumento y mejora de los sumideros de carbono (art. 26.1 LCC). Es decir, no sólo se trata de conservar los ya existentes, para los que la reforestación es el instrumento más adecuado, sino que se trata de ir más allá, ampliando estos sumideros de carbono mediante la forestación. Al fin y al cabo esta disposición está en plena consonancia con la preceptiva consideración de la Comisión Europea a la hora de proponer el objetivo climático de la UE para 2040 de ampliar los sumideros naturales a largo plazo (art. 4.5.j) del Reglamento (UE) 2021/1119. El problema es la falta de concreción de los medios para llevarlo a efecto.

\footnotetext{
${ }^{54}$ Una de las críticas que la doctrina más autorizada ha formulado a la LCC es que es un texto donde no priman los contenidos regulatorios directos, que se parece más a un plan de actuación gubernamental que a una norma jurídica, y en muy escasa medida regulador de relaciones jurídicas (LÓPEZ RAMÓN 2021: 17 y 20$)$.

${ }^{55}$ LÓPEZ RAMÓN (2021: 14).

${ }^{56}$ GARCÍA ASENSIO (2018.b: 331).
} 
En la misma línea se contempla una tercera medida de fomento, como es el incentivo de la participación de personas y entidades propietarias y gestoras públicas y privadas del sector forestal "en el aumento de la capacidad de captación de CO2 de los sumideros de carbono" (art. 26.2 LCC). En este caso su destinatario es plural, pues se configura como un mandato no sólo dirigido al Gobierno nacional sino también al resto de Administraciones públicas ${ }^{57}$. Lo ciertamente interesante es conocer el verdadero alcance de esta medida, pues el precepto, instalado en la generalidad ya señalada que es característica del texto de la LCC, no permite entender en qué puede consistir esa participación. En lo que respecto al sector forestal lo lógico es reconducirla a una política de fomento de las repoblaciones y forestaciones. Pero para este viaje no hacían falta nuevas alforjas, pues este tipo de medidas son ya antiguas en nuestro ordenamiento jurídico y su impulso depende fundamentalmente de la mera voluntad política y de la consiguiente dotación presupuestaria destinada a esos efectos. La respuesta nos la aporta la E. de M. (Apartado IV) de la LCC, cuando predica que "(...) se fomentarán sus cobeneficios como motor de desarrollo de las zonas rurales". Siempre instalada en la más absoluta generalidad e indefinición, parece querer apuntar a un posible mercado de externalidades, del que luego hablaremos al detalle. Lo que no se entiende es por qué no se ha trasladado esta idea de un modo explícito al texto normativo junto a un verdadero desarrollo con su correspondiente regulación.

Para llevar a efecto estas medidas de fomento, la LCC habilita diversas acciones (art. 26.3 LCC). En primer lugar, aquéllas que resaltan las externalidades positivas que proporcionan los sumideros forestales de carbono ${ }^{58}$. En nuestro ordenamiento jurídico actualmente sólo se contempla un mecanismo que capacita para pagar por la producción de dichas externalidades positivas, que no es otro que el contrato territorial. Una de las contraprestaciones del contrato territorial es la remuneración de las externalidades positivas generadas o contraprestación remuneratoria, por la que se permite obtener una ganancia o beneficio ${ }^{59}$. Precisamente en la figura

\footnotetext{
${ }^{57}$ LÓPEZ RAMÓN (2021: 15).

${ }^{58} \mathrm{El}$ art. 26.3 (LCC) distingue entre sumideros terrestres y marinos, y entre los primeros separa los agrarios de los forestales.

${ }^{59}$ GARCÍA ASENSIO (2020: 13).
} 
del contrato territorial debemos pensar al enfrentarnos al texto de la Disposición Final Séptima (LCC) cuando formula el mandato al Ejecutivo nacional para que en el plazo máximo de un año apruebe las normas necesarias para el desarrollo de la Ley 43/2003, de 21 de noviembre, de Montes, entre ellas, el mandato de su art. 65 "Incentivos por las externalidades ambientales" de regular los mecanismos y las condiciones para incentivar las externalidades positivas de los montes ordenados.

Otra acción, esta vez más concreta, es el uso de la biomasa de origen primario como fuente de materiales, así como "los productos forestales de los montes como materias primas con ciclo de vida óptimo, servicios ecosistémicos y energía de origen renovable y sostenible".

Mientras que esta relación de medidas, acciones y otras intervenciones sigue la apuntada línea genérica y abstracta, más cercana a un listado de buenas intenciones, como lo acredita tanto la falta de concreción en su planteamiento como de una fuente o un sistema de financiación ${ }^{60}$, en el art. 31.3 (LCC) se localiza una opción muy interesante a efectos forestales destinada a aplicarse en los procedimientos de contratación del sector público, que analizaremos más adelante.

El principio más importante para la consecución del objetivo de neutralidad climática es el de confluencia de todas las políticas públicas sectoriales, y se consagra en el Reglamento 2021/1119 (art. 5.3). En virtud del mismo todos los sectores han de desempeñar el papel que les corresponde para que dicho objetivo pueda ser una realidad, lo cual exige una necesaria transformación de los sectores de la energía, industria, edificación, transporte, agricultura, residuos y, por supuesto, el de la silvicultura ${ }^{61}$. De ahí el alcance de los sumideros naturales de carbono como una $\mathrm{SbN}$.

\footnotetext{
${ }^{60}$ Ciertamente el art. 30 (LCC), al hablar de los recursos públicos destinados a la lucha contra el cambio climático, apenas nos aporta ningún dato concreto, salvo el de financiación del sistema eléctrico, que, curiosamente, sí es objeto de financiación en fuente de ingreso y en porcentajes. Visto lo cual parece ser que este sector será el único que cuente con una verdadera financiación contra el cambio climático, resignándose el resto a pequeñas dotaciones simbólicas, si llega el caso.

${ }^{61}$ SORO MATEO (2020: 285 y 286).
} 


\section{V.- UNA OPORTUNIDAD PERDIDA: EL RÉGIMEN DE CÓMPUTO DE LAS ABSORCIONES POR LOS SUMIDEROS NATURALES. EL CASO DE LA HUELLA DE CARBONO}

Entre las ocasiones malogradas por la LCC se encuentra el no haber profundizado en la regulación de los montes como sumideros naturales de carbono. Más concretamente, y descartando la creación de un específico Fondo forestal nacional, que estaba previsto en el borrador de Ley de Cambio Climático que se manejaba en $2017^{62}$, nos referimos a la nueva consideración de la captura y almacenamiento biológico del carbono atmosférico por los montes como instrumento de mercado.

El punto de partida está claro: tal y como reconoce el Parlamento Europeo ${ }^{63}$, “(...) la prestación de servicios ecosistémicos como la captura de CO2, la promoción de la biodiversidad o la mejora del suelo no está remunerada adecuadamente en la actualidad, y que los silvicultores que se centran en transformar sus bosques en este sentido podrían estar gestionando en la actualidad sus bosques con pérdidas, a pesar de que prestan servicios ecosistémicos esenciales (...)". Por ello, la protección, restauración y la gestión forestal sostenible de los montes, tal y como reconoce la Nueva Estrategia Forestal de la UE para 2030 “(...) no sucederá sin la motivación, el compromiso y la acción de los propietarios y gestores forestales europeos, los principales cuidadores de los bosques. Lo correcto también debe ser económicamente viable (...)" (Apartado 3.4, primer párrafo). En el mismo sentido, el Pacto Verde Europeo de 2019 prevé que se ha de recompensar a los silvicultores por la gestión y almacenamiento del carbono (Apartado 2.1.6) ${ }^{64}$, unido a la indicación de la necesidad de desarrollar mercados internacionales de carbono como herramienta clave para crear incentivos económicos a la acción por el clima

\footnotetext{
${ }^{62}$ Lo comprobaremos en la práctica, pero quizás pueda hacer sus mismas o parecidas funciones el nuevo Fondo de carbono para una economía sostenible (FES-CO2) (FCPJ), pues uno de sus fines es el aumento de los sumideros de carbono (art. 91.2 de la Ley 2/2011, de 4 de marzo, de Economía Sostenible, conforme redacción dada por el Real Decreto-Ley 36/2020, de 30 de diciembre, por el que se aprueban medidas urgentes para la modernización de la Administración Pública y para la ejecución del Plan de Recuperación, Transformación y Resiliencia).

63 "Informe sobre la estrategia forestal europea: el camino a seguir" (2019/2157 (INI)), de 11 de septiembre de 2020, Ponente: Petri Sarvamaa (Apartado 9).

${ }^{64}$ Realmente habla de agricultores, pero debe recordarse que en el ámbito de la UE la agricultura es un sector difuso y engloba también a la silvicultura.
} 
(Apartado 3). De ahí que sea ineludible para el éxito de la silvicultura del carbono rentabilizar las externalidades que los montes ofrecen a la sociedad.

Este instrumento de mercado consistiría en que los sectores económicos que no pueden reducir emisiones tengan la opción de compensarlas adquiriendo equivalentes en capturas de $\mathrm{CO} 2$ realizadas por los montes dada su condición de sumideros, poniéndolas en el mercado a cambio de una contraprestación económica. Desde luego que los mercados no son la panacea al problema del cambio climático, ya que tienen sus fallos, pero son los que saben y pueden repartir los servicios de los ecosistemas con eficiencia e impactar en gran cantidad de personas y negocios ${ }^{65}$. Ya se explicó en su momento ${ }^{66}$, que no cabe en nuestro ordenamiento jurídico pues la Unión Europea no se atreve a integrar UTCUTS en el marco estratégico post-2020, pues, como confiesa en los Considerandos del Reglamento (UE) 2018/841, darle tratamiento material de sumidero y, así compensar el sistema general de emisiones de gases de efecto invernadero67, no se admite al considerar que las absorciones que se produzcan son reversibles, tienen un menor potencial de mitigación, carecen de previsibilidad y su rentabilidad es a largo plazo ${ }^{68}$.

Esta falta resulta aún más llamativa si cabe cuando se tiene previsto que aprovechar el potencial de absorción de gases de efecto invernadero por parte de los sumideros naturales para abordar la necesidad de atajar las emisiones en los sectores difusos no energéticos, contemplado expresamente en el Plan Nacional Integrado de Energía y Clima 2021-203069 (en adelante, PNIEC),

\footnotetext{
${ }^{65}$ LOZANO CUTANDA y RÁBADE BLANCO (2013: 337).

${ }^{66}$ GARCÍA ASENSIO (2018.b: 367 a 371).

${ }^{67}$ RODRÍGUEZ-CHAVES MIMBRERO (2017: 428), quien expone que la posición de España es contraria a este criterio, que es el que al fin y al cabo se ha impuesto en el Reglamento (UE) 2018/841, y parece ser que negocia su modificación para que termine computando la gestión forestal sostenible como sumidero de tal modo que compense el sistema general de emisiones de esos gases (RODRÍGUEZCHAVES MIMBRERO (2018: 632), señalando, además, que en la trastienda de la decisión de la Comisión se encontraba también la posición de algún país eminentemente forestal que pretendía no reducir las emisiones y simplemente conformarse con la compensación de dichas emisiones por el efecto sumidero de sus bosques). RODRÍGUEZ ÁLVAREZ (2017: 1) confirma que en Europa no están incluidos los proyectos forestales en ninguna Directiva, lo que implica la inexistencia de ese mercado de carbono.

${ }^{68}$ GARCÍA ASENSIO (2018.b: 368 y 369).

${ }^{69}$ Aprobada por Acuerdo del Consejo de Ministros de 16 de marzo de 2021, ordenándose su publicación por Resolución de 25 de marzo de 2021, conjunta de la Dirección General de Política Energética y Minas y de la Oficina Española de Cambio Climático. Esta referencia aparece en su pág. 14, insertándose los sumideros forestales como Medida 1.24 dentro de la Dimensión de descarbonización (pág. 81). Tangencialmente se incluye también en otras medidas, como la 1.19 "Generación de conocimiento, divulgación y sensibilización”, pues “(...) supone ahondar en la concienciación de los ciudadanos y
} 
aunque, bien es cierto, en ninguna de las específicas medidas contempladas en el mismo persigue la creación de este tipo de instrumentos ${ }^{70}$. No obstante, es frecuente que en los Planes y Programas que inundan actualmente nuestro ordenamiento jurídico se hagan citas a los sumideros forestales, sin mayor consecuencia práctica. Es el caso del Plan Estatal Marco de Gestión de Residuos 2016-2022 ${ }^{71}$, que se limita a indicar que el uso de compost en el suelo contribuye a la creación de sumideros adicionales de carbono en los suelos, y por ello a la protección del clima (apartado 6.6); y del Plan estratégico del patrimonio natural y de la biodiversidad 2011-2017, aprobado por Real Decreto $1274 / 2011$, de 16 de septiembre, que compendia los conceptos ya aceptados sobre los montes como sumideros de carbono. No ocurre lo mismo con el Plan de contabilidad forestal nacional para España, incluyendo el nivel forestal de referencia 2021-2025, pues profundiza en la materia, especialmente desde un punto de vista más técnico que jurídico.

Precisamente para alcanzar los objetivos de acelerar la transición hacia una economía baja en carbono, dar cumplimiento al Acuerdo de París y avanzar hacia la consecución de la Unión de la Energía en sus cinco dimensiones (descarbonización, eficiencia energética, seguridad energética, mercado interior e $\mathrm{I}+\mathrm{i}+\mathrm{C}$ ), la UE dictó el Reglamento UTCUTS. Este adelanto de la UE respecto a España será más evidente a finales del presente año 2021, pues la Comisión tiene anunciado que promoverá esquemas de remuneración relacionados con los bosques en un plan de acción para el cultivo de carbono y la certificación de eliminación de carbono ${ }^{72}$.

De haber actuado con valentía el legislador español, hubiera supuesto un salto cualitativo, con especial incidencia en otro instrumento actualmente existente, aunque algo desconocido, como es la huella de carbono, pues se le hubiera dotado de una dimensión de la que ahora carece, como vamos a exponer.

sectores público y privado sobre la necesidad de abordar el proceso de descarbonización y difundir las herramientas, tecnologías o prácticas para reducir el consumo de energías fósiles, incrementar la aportación de energías renovables, reducir las emisiones de GEI y aprovechar el potencial de los sumideros de carbono".

${ }^{70}$ PNIEC, pág. 128.

${ }^{71}$ Aprobado mediante Acuerdo del Consejo de Ministros de 6 de noviembre de 2015.

${ }^{72}$ Apartado 3.4 de la Nueva Estrategia Forestal de la UE para 2030. 
La huella de carbono es un sistema de compensación basado en proyectos forestales ante la ausencia de un mercado voluntario de carbono que permita transmitir los derechos de captura y almacenamiento de CO2 atmosférico. Se concibe como la totalidad de gases de efecto invernadero provenientes por efecto directo e indirecto de la actividad de una organización ${ }^{73}$. Como puede observarse, la creación de la huella de carbono implica de partida el reconocimiento de los bosques como sumideros de carbono. Su elemento subjetivo es una organización, entendiendo como tal no sólo personas jurídicas, como podría desprenderse del uso de este término (lo que aconseja su sustitución), sino también las personas físicas, siempre que desarrollen una actividad económica y sean generadoras de emisiones de gases de efecto invernadero, con actividad en el territorio nacional ${ }^{74}$. Al ser titulares de una actividad económica, las personas físicas tienen la obligación de estar dados de alta como trabajadores autónomos ${ }^{75}$. No obstante, tanto en Cataluña como en el Sistema Andaluz de Compensaciones de Emisiones (SACE) ${ }^{76}$ este ámbito subjetivo se modifica. En el primer caso se restringe sólo a los productos, sin incluir las organizaciones ${ }^{77}$. Y en el segundo se amplía a eventos, actividades o al ciclo de vida de un producto o servicio ${ }^{78}$.

\footnotetext{
${ }^{73}$ Art. 1.2.a) (Real Decreto 163/2014).

${ }^{74}$ Art. 3.1 (Real Decreto 163/2014, ya calendado). Alguna normativa, empero, hace referencia a la huella de carbono no de la organización sino de la instalación o producto, como es el caso de las inscripciones en el Registro electrónico del régimen económico de energías renovables, tanto en estado de preasignación como de explotación, en cuya solicitud deberá ajustarse la información sobre la huella de carbono de las instalaciones (art. 13 y 14 de la Orden TED/1161/2020, de 4 de diciembre, por la que se regula el primer mecanismo de subasta para el otorgamiento del régimen económico de energías renovables y se establece el calendario indicativo para el periodo 2020-2025).

${ }^{75}$ De ahí su mención en el apartado a) del art. 3.1 (Real Decreto 163/2014), ya que, según el art. 1.1, en relación con el art. 5, ambos de la Ley 20/2007, de 11 de julio, del Estatuto del trabajo autónomo, las personas físicas que realicen de forma habitual, personal, directa, por cuenta propia y fuera del ámbito de dirección y organización de otra persona, sea a tiempo completo o a tiempo parcial, una actividad económica o profesional a título lucrativo, den o no ocupación a trabajadores por cuenta ajena, deben cumplir con sus obligaciones fiscales y tributarias. Y conforme el art. 2.1 de la Orden EHA/1274/2007, de 26 de abril, quienes hayan de formar parte del Censo de empresarios, profesionales y retenedores deberán presentar una declaración de alta en el mismo, concretamente quienes desarrollen o vayan a desarrollar en territorio español actividades empresariales o profesionales.

${ }^{76}$ Creado por el art. 51 de la Ley $8 / 2018$, de 8 de octubre, de medidas frente al cambio climático y para la transición hacia un nuevo modelo energético en Andalucía.

${ }^{77}$ Art. 56 (Ley 16/2017), ordenando al ejecutivo catalán que debe establecer las bases para un sistema de evaluación de la huella de carbono de productos.

${ }^{78}$ Apartado l) del Anexo de la Ley 8/2018. Esta circunstancia no es nueva, por cuanto ya el apartado $6^{\circ}$ del Anexo IV de la Ley 21/2013, de 9 de diciembre, de Evaluación de Impacto Ambiental, ya contemplaba "una evaluación adecuada de la huella de carbono asociada al plan o programa".
} 
En principio y con carácter general se trata de un sistema voluntario ${ }^{79}$, como todas las técnicas de certificación ${ }^{80}$, e intencional, pues los sujetos afectados han optado por realizar actividades dirigidas a la reducción o compensación de emisiones de gases de efecto invernadero ${ }^{81}$, no sólo de dióxido de carbono. Además se trata de un sistema formal, pues sólo tendrá efectos legales si se inscriben en el Registro de huella de carbono, compensación y proyectos de absorción de dióxido de carbono, el cual tendrá carácter administrativo, público ${ }^{82}$ y constitutivo, pues sólo mediante la inscripción en el mismo pueden obtener un reconocimiento legal y acceder al uso de un sello de marca, que es de titularidad del Ministerio correspondiente ${ }^{83}$.

Para la operatividad y cálculo de la huella de carbono, el Registro se divide en tres secciones, la primera sobre la propia huella de carbono y los compromisos de reducción de emisiones de gases de efecto invernadero, la segunda sobre proyectos de absorción de $\mathrm{CO} 2$, y la tercera sobre compensación de huella de carbono ${ }^{84}$. Respecto a la Sección a), se podrán inscribir las verificaciones realizadas por entidades acreditadas para la ISO $14064^{85}$ y otras similares, así como las entidades independientes acreditadas por la ONU en el marco de los mecanismos de flexibilidad del Protocolo de Kyoto ${ }^{86}$. Pero ahora nos interesan más las otras dos secciones, pues la b) permite inscribir las absorciones de $\mathrm{CO} 2$ generadas en territorio nacional en proyectos de actividades relacionadas con UTCUTS y que supongan el aumento del carbono almacenado ${ }^{87}$, es decir, se pueden valorar las funciones de sumidero de nuestros montes. De este modo, el cálculo de estas absorciones se realizará en base a las directrices y orientaciones sobre buenas prácticas del Grupo Intergubernamental de Expertos sobre el Cambio Climático (IPCC) que se utilicen para la elaboración

\footnotetext{
${ }^{79}$ Art. 3.1.a) (Real Decreto 163/2014).

${ }^{80}$ GARCÍA ASENSIO (2018.b: 354 y 355).

${ }^{81}$ Art. 3.1.c) (Real Decreto 163/2014).

${ }^{82}$ Art. 2 (Real Decreto 163/2014).

${ }^{83}$ Art. 3.2 (Real Decreto 163/2014). Algunas Comunidades Autónomas han creados sus propios registros de huella de carbono, como la andaluza (art. 51 Ley 8/2018), la balear (art. 28 Ley 10/2019) y la asturiana (Decreto 40/2021), cuya titularidad corresponde lógicamente a las mismas.

${ }^{84}$ Art. 2 (Real Decreto 163/2014).

${ }^{85} \mathrm{El}$ art. 2.j) (Decreto 40/2021) concreta más y hace referencia a la norma UNE EN ISO-3 “Gases de efecto invernadero. Parte $3^{a}$ : Especificación con orientación para la validación y verificación de declaraciones sobre gases de efecto invernadero".

${ }^{86}$ Art. 6.3 (Real Decreto 163/2014), aunque no es preceptivo para las PYMES (art. 9.4.2 ${ }^{\circ}$ ).

${ }^{87}$ Art. 7.1 (Real Decreto 163/2014).
} 
del Inventario Nacional de Gases de Efecto Invernadero ${ }^{88}$. Es decir, por primera vez en nuestro país, se permite calcular a efectos oficiales las absorciones de carbono atmosférico. Pero el Registro va más allá y, a través de la Sección c), permite inscribir operaciones de compensaciones de la huella de carbono inscritas en la Sección a) con proyectos de absorción de dióxido de carbono recogidos en la Sección b) ${ }^{89}$. Dado que la compensación es un instituto jurídico consistente en que dos personas por derecho propio son recíprocamente acreedoras y deudoras la una de la otra (art. 1195 Cc), lo que el Registro permite es realizar y constatar el cálculo de detraer de las emisiones de gases de efecto invernadero de una organización las absorciones que él o un tercero realizan ${ }^{90}$. Esta compensación es potestativa, en contraste con la reducción de emisiones contemplada en la Sección a), que es preceptiva.

Además, por cada proyecto de absorción se exige una cesión inicial gratuita de una cantidad de absorciones a una bolsa de garantía, equivalente a un 10 por 100 de las absorciones disponibles. Esta bolsa de garantía es el medio diseñado para hacer frente a algunos de los casos de reversibilidad a que hemos hecho mérito anteriormente, es decir, que el monte sufra algún tipo de contingencia que provoque su pérdida en el plazo de 30 años, con la consiguiente liberación del carbono absorbido hasta ese momento. Así, la organización puede optar por sustituir las absorciones perdidas por las de otro proyecto, y, en otro caso y si la pérdida es por fuerza mayor, se le restituirán a cargo de la bolsa de garantía a través de una nueva compensación. Si dicha pérdida no fuera por causas de fuerza mayor se anulará la compensación con la posibilidad de ejercer las acciones que considere oportunas ${ }^{91}$.

\footnotetext{
${ }^{88}$ Art. 7.3 (Real Decreto 163/2014).

${ }^{89}$ Art. 8.1 (Real Decreto 163/2014). También permite esta operación con los proyectos de reducción de emisiones de gases de efecto invernadero realizados por un tercero y recogidas en la Sección a).

${ }^{90}$ En similares términos se considera en el apartado h) del art. 4 de la balear Ley 10/2019: "la adquisición de una determinada cantidad equivalente de $\mathrm{CO} 2$ que procede de los proyectos de absorción de este gas o de los proyectos de reducciones de emisiones realizados por un tercero", y el art. 2.d) del asturiano Decreto 40/2021. Más desarrollado es el concepto del SACE: "En relación con un servicio, proceso o producto cuya prestación o elaboración da lugar a una emisión neta de gases de efecto invernadero (GEI) durante su ciclo de vida, la compensación se basa en otro proceso o mecanismo, ajeno a dicho ciclo de vida, que dé lugar a una absorción de carbono, que sea posible evaluar y certificar, en cantidad equivalente a las emisiones de GEI producidas por el primero" (apartado d) del Anexo de la Ley 8/2018). ${ }^{91}$ MINISTERIO DE AGRICULTURA Y PESCA, ALIMENTACIÓN Y MEDIO AMBIENTE y OFICINA ESPAÑOLA DE CAMBIO CLIMÁTICO (OECC). (Enero de 2018). Información sobre la sección de proyectos de absorción de dióxido de carbono. Obtenido de Versión 5: http://www.magrama.gob.es/es/cambio-climatico/temas/mitigacion-politicas-y-
} 
Dado que uno de los objetivos de la huella de carbono es añadir valor a las actividades forestales ${ }^{92}$, la principal cuestión que debemos plantearnos en este momento es conocer la eventual virtualidad práctica de la huella de carbono y su alcance. A nivel nacional, la huella de carbono es simplemente una marca de calidad como consecuencia de una específica técnica de certificación, con una mera intención de fomentar y sensibilizar a la sociedad en la lucha contra el cambio climático y, con ello, contribuir a lograr una sociedad descarbonizada. Es sólo un medio de acreditación y visibilización del compromiso de la empresa con la mitigación del cambio climático. Éste es el sentido en que hay que enfocar la finalidad expresada en el texto articulado del Real Decreto 163/2014 atribuida a la huella de carbono sobre "(...) incrementar las absorciones por los sumideros de carbono en el territorio nacional y a facilitar de esta manera el cumplimiento de los compromisos internacionales asumidos por España en materia de cambio climático". Como puede advertirse, se limita a una función de fomento, pero carece de trascendencia práctica tanto a la hora de cumplir con las obligaciones de emisión como de considerar transmisibles los derechos de absorción.

Estas afirmaciones deben ser objeto, no obstante, de la debida precisión. Así, por mandato expreso del art. 8.2 (Real Decreto 163/2014) ${ }^{93}$, las obligaciones que tienen los agentes emisores de entregar los derechos de emisión derivados de la Ley $1 / 2005$, de 9 de marzo, por la que se regula el régimen del comercio de derechos de emisión de gases de efecto invernadero, quedan incólumes y son independientes de toda operación de compensación, llegando a tachar expresamente de inválida toda operación que sea contraria a esta disposición. Por ello las compensaciones que se produzcan en la huella de carbono no se computan a efectos de la inexistencia de obligación de entregar derechos de emisión relativos a emisiones cuya captura esté comprobada y que se hayan transportado para su almacenamiento permanente a una

medidas/documentoapoyopa_tcm7-330264.pdf. Algunos de estos aspectos no se recogen en el Real Decreto 163/2014. En cambio, en Asturias el art. 2.b) y Disposición Adicional Primera del Decreto 40/2021 aprenden de la experiencia del Registro estatal y ya han incorporado al texto legal alguna de estas dinámicas.

92 Art. 1.2.c) (Real Decreto 163/2014). Lo que queda fuera del ámbito del Registro, por silencio del mismo, son las condiciones del acuerdo de cesión que se alcance entre las partes, sin reflejar variables tales como el precio.

${ }^{93}$ Disposición reiterada para Asturias por el art. 12.2 (Decreto 40/2021). 
instalación con una autorización vigente de conformidad con la legislación en vigor sobre almacenamiento geológico de dióxido de carbono ${ }^{94}$, algo lógico teniendo en cuenta que con los montes estamos ante un sumidero natural y no geológico. Como se ve existe una diferencia de trato clara y palpable en detrimento de los sumideros naturales. Ciertamente, el art. 8.2 es la previsión normativa más importante del Real Decreto 163/2014 por cuanto resulta clave para entender la dimensión práctica de la huella de carbono, pues realmente no se ha producido tal compensación, salvo a efectos internos de la huella de carbono, por lo que en este sentido se confirma su carácter de mero sello de marca. En definitiva, a los efectos del cómputo de la contabilidad de la reducción de emisiones sigue sin reconocerse la posibilidad de comerciar y transmitir libremente los esfuerzos de captura y almacenamiento de $\mathrm{CO} 2$ por parte de nuestros silvicultores, no siendo la huella de carbono el instrumento más adecuado para ello en su actual configuración.

Por otro lado, y en lo referente a la transmisibilidad de las absorciones, se ha de matizar que al permitirse una compensación con absorciones de terceros en la Sección b), se está reconociendo un derecho de enajenación de las mismas, confirmado con el uso del término "adquirido" que se utiliza en el art. 9.4.c).10 (Real Decreto 163/2014). Pero es preciso señalar que esta transmisión sólo puede hacerse en el marco del Registro de la huella de carbono y exclusivamente a través del instituto de la compensación como única operación de transmisibilidad aceptada, lo que supone una limitación esencial, ya que no existe libertad de mercado y, lo que es más importante, su adquisición sólo tiene una relación interna y nunca a efectos de citada contabilidad, como ya se ha dejado sentado.

Quizás consciente el legislador de esta destacada limitación, realiza un esfuerzo para dotar de contenido a la huella de carbono, e intenta, dentro de los márgenes que le permite el ordenamiento interno concederle alguna relevancia aparte de la mera publicitaria. De ahí la previsión contenida en el art. 10 (Real Decreto 163/2014) sobre la consideración de la huella de carbono en el ámbito de la contratación en el sector público. Dado que los art. 28.2, 122.2 y 124 de la Ley 9/2017, de 8 de noviembre, de Contratos del Sector Público, por

\footnotetext{
94 Art. 27.3 (Ley 1/2005).
} 
la que se transponen al ordenamiento jurídico español las Directivas del Parlamento Europeo y del Consejo 2014/23/UE y 2014/24/UE, de 26 de febrero de 2014, permiten exigir aspectos de tipo ambiental en el procedimiento de licitación se podrá establecer obligaciones relativas a la huella de carbono. Esta previsión se ha generalizado, especialmente a raíz de las diversas estrategias nacionales y del esfuerzo en la mitigación del cambio climático. Así, basándose en que la Estrategia Europa 2020 marca que la contratación pública desempeña un papel clave al configurarse como un instrumento para conseguir un crecimiento inteligente, sostenible e integrador, y en el citado art. 10 (Real Decreto 163/2014), en el ámbito de la Administración estatal ya se ha establecido que debe adquirirse bienes, servicios y productos con la menor huella de carbono posible calculada de forma comparable, para lo cual se valorará la inscripción del licitador en el Registro de huella de carbono o uno similar $^{95}$. Algunas Comunidades Autónomas han reiterado esta posibilidad, como Asturias ${ }^{96}$, o la han llevado más lejos como las Islas Baleares, al imponer imperativamente que todas las Administraciones públicas introduzcan "como criterios de valoración la inscripción de los licitadores en los registros públicos de huella de carbono y la reducción o la compensación de sus emisiones"97. En todo caso, lo que ya no tiene marcha atrás es la incorporación, como prescripciones técnicas particulares en los pliegos de contratación, criterios de reducción de emisiones y de huella de carbono dirigidos específicamente a la lucha contra el cambio climático ${ }^{98}$.

Empero, en los últimos textos normativos climáticos se está despojando de la condición de voluntariedad a la huella de carbono, como es el caso de las grandes y medianas empresas que operan en las Islas Baleares, tanto si están

\footnotetext{
${ }^{95}$ Apartado Sexto del Plan de Contratación Pública Ecológica de la Administración General del Estado, sus organismos autónomos y las entidades gestoras de la Seguridad Social (2018-2025), aprobado por Acuerdo del Consejo de Ministros de 7 de diciembre de 2018, y publicado por Orden PCI/86/2019, de 31 de enero. Este Plan ya deja claro que considera al Registro de huella de carbono como garantizador de que el licitador (organización) no sólo calcula las emisiones derivadas de su actividad, sino que también tiene en marcha un plan de reducción.

${ }^{96}$ Disposición Adicional Segunda (Decreto 40/2021).

${ }^{97}$ Art. 68.3 (Ley 10/2019).

${ }^{98}$ Art. 31.1 (LCC), para lo cual los Ministerios de Transición Ecológica y el Reto Demográfico y el de Hacienda elaborarán un catálogo de prestaciones en cuya contratación se tendrán en cuenta los criterios de lucha contra el cambio climático mencionados en este apartado y en el que se identificarán tales criterios de reducción de emisiones y de huella de carbono, incluidos los relacionados con una alimentación sostenible y saludable.
} 
sometidas al régimen de comercio de emisiones de gases como si no, a quienes se les obliga a calcular y acreditar anualmente la correspondiente huella de carbono en las actividades que lleven a cabo en ese ámbito territorial ${ }^{99}$, incluso bajo pena de sanción por infracción leve ${ }^{100}$. En esta misma línea se acaba de pronunciar el legislador estatal, pues en la Disposición Final Duodécima (LCC) previene que reglamentariamente, y a través de una modificación del Real Decreto 163/2014, ciertas empresas han de calcular y publicar su huella de carbono, con obligación además de elaborar y publicar un plan de reducción de emisiones de gases de efecto invernadero. Establecer este tipo de exigencias en este momento es del todo punto criticable, pues el operador no tiene posibilidad de reflejar en su contabilidad a efectos del citado régimen de comercio de emisiones de gases las adquisiciones de absorciones, lo que carece de sentido al quebrar el criterio de coherencia que supondría deducir unas absorciones tanto en el citado régimen del mismo modo que se hace con la huella de carbono. Además, existe consenso en que un sistema de mercado obligatorio de compensación no alcance las mínimas cotas de rentabilidad para financiar un proyecto forestal y, por tanto, no sean viables ${ }^{101}$. De ahí que alguna normativa regule acerca de la huella de carbono desde una política de fomento, no de imposición o coercitiva, como la Ley 7/2019, de 29 de noviembre, de Economía Circular de Castilla-La Mancha, pues uno de sus objetivos es incentivar el cálculo de la huella de carbono en todas las actividades económicas (art. 4.0)).

\section{VI.- EL RECIENTE REDIMENSIONAMIENTO JURÍDICO DE LA REPOBLACIÓN FORESTAL}

Sin perjuicio de lo ya expuesto, la repoblación forestal ha sido sometida últimamente a un redimensionamiento en su tratamiento jurídico, precisamente en virtud de su relación con la mitigación del cambio climático y de modo

\footnotetext{
${ }^{99}$ Apartado a) del art. 25 (Ley 10/2019). Como novedad, en esta Comunidad Autónoma se promueve que voluntariamente se calcule la huella de carbono en los proyectos de nuevas edificaciones (art. 31.1 Ley 10/2019).

${ }^{100}$ Art. 93.j) (Ley 10/2019).

${ }^{101}$ RODRÍGUEZ ÁLVAREZ (2017: 3 y 9), explicando que cuando una empresa decide compensar sus emisiones trata de minimizar costes, de ahí que los proyectos forestales no logren introducirse más, pues el precio de su tonelada de carbono es más alta que otros proyectos, como los eólicos o hidráulicos, y si se reducen ya no serían rentables.
} 
especial como consecuencia de ésta. Extremo al que también se ha visto abocado por cuanto se ha constatado una baja tasa de repoblaciones forestales en la actualidad ${ }^{102}$. Desde luego que no ha sido una operación drástica, sino que, como se ha visto, venía siendo decantada en las últimas décadas. Pero también es cierto que en los últimos años se ha acelerado y dotado de nuevos contenidos y objetivos, en una operación de redimensionamiento que vamos a estudiar a continuación.

Dos aldabonazos impulsan este proceso: el Acuerdo de París de 2015 y los Objetivos de Desarrollo Sostenible (ODS), más conocidos como Agenda $2030^{103}$. En cuanto al primero, instaba la adopción de medidas para aplicar y apoyar, también mediante los pagos basados en los resultados, el marco establecido en las orientaciones y decisiones pertinentes ya adoptadas en el ámbito de la Convención respecto de los enfoques de política y los incentivos positivos para reducir las emisiones debidas a la deforestación y la degradación de los bosques, y de la función de la conservación, la gestión sostenible de los bosques (art. 5.2). Precisamente en su desarrollo, la inclusión del sector del uso de la tierra, el cambio de uso de la tierra y la silvicultura en el Marco sobre Clima y Energía para 2030 a través del Reglamento UTCUTS se considera un reflejo del reconocimiento en el Acuerdo de París del papel de las fuentes y los sumideros en la acción contra el cambio climático ${ }^{104}$.

Respecto a la Agenda 2030 es preciso atender al ODS15, dedicado específicamente a proteger, restablecer y promover el uso sostenible de los ecosistemas terrestres, gestionar sosteniblemente los bosques, luchar contra la desertificación, detener e invertir la degradación de las tierras y detener la pérdida de biodiversidad. Su justificación es toda una declaración de intenciones: "la deforestación y la desertificación -provocadas por las actividades humanas y el cambio climático- suponen grandes retos para el desarrollo sostenible y han afectado a las vidas y los medios de vida de millones de personas en la lucha contra la pobreza. Se están poniendo en marcha medidas destinadas a la gestión forestal y la lucha contra la

\footnotetext{
102 PNIEC, pág. 125.

103 Aprobados por Resolución de la Asamblea General de la ONU 70/1, de 25 de septiembre de 2015,

"Transformar nuestro mundo: la Agenda 2030 para el Desarrollo Sostenible".

${ }^{104}$ PNIEC, pág. 40.
} 
desertificación". Es decir, se propone, por un lado, evitar la pérdida de cubierta arbórea existente $y$, por otro, avanzar en la recuperación de las extensiones boscosas al luchar contra la desertificación. Para estas dos actuaciones se apuntan dos medidas específicas y diferenciadas: respecto a la primera, se acude a la gestión forestal sostenible, que debe comprender la reforestación; y en cuanto a la segunda, debe instrumentalizarse mediante la forestación, es decir, la sustitución de un terreno desértico por otro poblado de especies forestales, que es la principal vía de ganar terreno al desierto.

Para alcanzar el citado ODS la ONU ha establecido diversas metas, destacando las siguientes, a los efectos que ahora nos interesan: (i) De aquí a 2020, asegurar la conservación, el restablecimiento y el uso sostenible de los ecosistemas terrestres y los ecosistemas interiores de agua dulce y sus servicios, en particular los bosques, los humedales, las montañas y las zonas áridas, en consonancia con las obligaciones contraídas en virtud de acuerdos internacionales (meta 15.1); (ii) De aquí a 2020, promover la puesta en práctica de la gestión sostenible de todos los tipos de bosques, detener la deforestación, recuperar los bosques degradados y aumentar considerablemente la forestación y la reforestación a nivel mundial (meta 15.2); (iii) De aquí a 2030, luchar contra la desertificación, rehabilitar las tierras y los suelos degradados, incluidas las tierras afectadas por la desertificación, la sequía y las inundaciones, y procurar lograr un mundo con efecto neutro en la degradación de las tierras (meta 15.3); (iv) Adoptar medidas urgentes y significativas para reducir la degradación de los hábitats naturales, detener la pérdida de la diversidad biológica y, para 2020, proteger las especies amenazadas y evitar su extinción (meta 15.5); y (v) Movilizar recursos considerables de todas las fuentes $\mathrm{y}$ a todos los niveles para financiar la gestión forestal sostenible y proporcionar incentivos adecuados a los países en desarrollo para que promuevan dicha gestión, en particular con miras a la conservación y la reforestación (meta 15.b).

Como puede observarse se trata de una relación de objetivos, técnica muy eficaz a nivel internacional a fin de informar la normativa nacional, que tiene la obligación de superar el nivel de los principios y positivizar medidas concretas en orden a la consecución de los citados principios. De ahí la oportunidad en 
gran medida perdida con la LCC que, como ya se ha justificado, se mantiene anclada en el nivel de los principios, desaprovechando la ocasión para articular un sistema normativo de aplicación práctica.

Empero, lo que está claro es que este conjunto de objetivos está produciendo un redimensionamiento de la política forestal, la cual se materializa en varios frentes, que analizaremos a continuación.

\section{1.- Un nuevo principio para el Derecho Forestal.}

Dentro de la gestión forestal sostenible se está asumiendo un nuevo principio, que ya tiene cabida en la normativa comunitaria y, en consecuencia, en la española, como es el de "no causar un perjuicio significativo", en adelante principio DNSH ${ }^{105}$, que según el art. 2.6 (Reglamento 2021/241 del Parlamento Europeo y del Consejo, de 12 de febrero de 2021, por el que se establece el Mecanismo de Recuperación y Resiliencia) supone no apoyar o llevar a cabo actividades económicas que causen un perjuicio significativo a alguno de los objetivos medioambientales, en su caso, en el sentido del art. 17 del Reglamento (UE) 2020/852, del Parlamento y del Consejo, de 18 de junio, relativo al establecimiento de un marco para facilitar las inversiones sostenibles y por el que se modifica el Reglamento (UE) 2019/2088, más conocido como Reglamento de taxonomía ${ }^{106}$. Su origen se encuentra en el mandamiento verde de "no ocasionarás daños" contenido en el Pacto Verde Europeo (Apartado 2.2.5), y que la UE pretende hacerlo extensivo a todas sus iniciativas, obligando a que la exposición de motivos que acompaña a todas las propuestas legislativas y actos delegados incluirá una sección específica en la que se explicará la forma en que cada iniciativa respeta dicho principio.

Su aplicación al ámbito forestal viene dado al prevenir dicho Reglamento que ninguna ejecución de las reformas e inversiones incluidas en el Plan de

\footnotetext{
${ }^{105}$ Por sus siglas en inglés "Do Not Significant Harm" (art. 1.3 del Real Decreto 692/2021, de 3 de agosto, por el que se regula la concesión directa de ayudas para inversiones a proyectos singulares locales de energía limpia en municipios de reto demográfico (PROGRAMA DUS 5000), en el marco del Programa de Regeneración y Reto Demográfico del Plan de Recuperación, Transformación y Resiliencia).

${ }^{106}$ Llamado así por cuanto establece un marco para facilitar las inversiones sostenibles mediante la implantación de un sistema de clasificación (o "taxonomía") de las actividades económicas ambientales sostenibles, según nos informa la Guía técnica.
} 
Recuperación, Transformación y Resiliencia causará un perjuicio significativo a los seis objetivos ambientales definidos en el Reglamento de taxonomía, entre los que se encuentra tanto la mitigación del cambio climático como la protección y recuperación de la biodiversidad y los ecosistemas ${ }^{107}$. Aun cuando su origen, como estamos viendo, se limita a las actuaciones que conforman el referido Plan, su aplicación debe entenderse ampliada a toda actividad forestal, pues su justificación queda plenamente incardinada en los diferentes principios ambientales recogidos en el art. 45 (CE), pues es común su razón de ser, y el sector forestal queda afectado dentro de su ámbito objetivo.

Estamos ante un principio de configuración horizontal, es decir, que se aplica a todos los supuestos y de modo idéntico. Ello es así, no sólo por su propia naturaleza, sino por mandato expreso del art. 5.2 (Reglamento 2021/241): el MRR sólo apoyará aquellas medidas que respeten este principio. Este carácter horizontal tiene su fundamento en otros dos principios también horizontales de la $\mathrm{UE}^{108}$, de los que se deriva esta naturaleza: el de igualdad de oportunidades y de no discriminación, como clara regla de imparcialidad que debe presidir su aplicación, y en el de desarrollo sostenible. La vinculación de este principio con el DNSH viene dada expresamente por el art. 3.b) (Reglamento 2020/852), pues la determinación del grado de sostenibilidad medioambiental de una inversión, vendrá dado cuando no se cause ningún perjuicio significativo a alguno de los citados objetivos medioambientales ya expuestos. Al fin y al cabo, el principio de desarrollo sostenible trata de evitar o reducir los efectos perjudiciales para el Medio Ambiente de las intervenciones y de garantizar resultados en beneficios netos de carácter social, medioambiental y climático, y está dotado de un contenido concreto, pues persigue orientar las inversiones hacia las opciones más sostenibles y eficientes en cuanto a los recursos; evitar las inversiones que puedan tener un impacto negativo importante de carácter medioambiental o climático, y respaldar las acciones que contribuyan a reducir

\footnotetext{
107 Art. 9, reproducido en el art. 5 de la Orden HFP/1030/2021, de 29 de septiembre, por la que se configura el sistema de gestión del Plan de Recuperación, Transformación y Resiliencia.

${ }^{108}$ Apartados 5.2 y 5.3 del Anexo I del Reglamento (UE) núm. 1303/2013, del Parlamento Europeo y del Consejo, de 17 de diciembre de 2013, por el que se establecen disposiciones comunes relativas al Fondo Europeo de Desarrollo Regional, al Fondo Social Europeo, al Fondo de Cohesión, al Fondo Europeo Agrícola de Desarrollo Rural y al Fondo Europeo Marítimo y de la Pesca, y por el que se establecen disposiciones generales relativas al Fondo Europeo de Desarrollo Regional, al Fondo Social Europeo, al Fondo de Cohesión y al Fondo Europeo Marítimo y de la Pesca, y se deroga el Reglamento (CE) no 1083/2006 del Consejo.
} 
las repercusiones restantes; cuando se comparen los costes de "ciclos de vida" de opciones alternativas de inversión, adoptar una perspectiva a largo plazo; y recurrir en mayor medida a la contratación pública ecológica ${ }^{109}$.

A diferencia de otros principios ambientales, y debido a la importante relevancia económica que subyace en los proyectos financiados por el Plan y que deben sujetarse imperativamente al mismo, el legislador europeo ha concretado los límites del principio, aunque bajo una formulación negativa, ya que lo que realmente positiviza son los supuestos en que se incurre en "perjuicio significativo". Esta operación se contiene en el art. 17.1 (Reglamento 2020/852) y sistematizada en el apartado 1 de la Comunicación de la Comisión 2021/C58/01, a saber:

1. se considera que una actividad causa un perjuicio significativo a la mitigación del cambio climático si da lugar a considerables emisiones de gases de efecto invernadero (GEI);

2. se considera que una actividad causa un perjuicio significativo a la adaptación al cambio climático si provoca un aumento de los efectos adversos de las condiciones climáticas actuales y de las previstas en el futuro, sobre sí misma o en las personas, la naturaleza o los activos;

3. se considera que una actividad causa un perjuicio significativo a la utilización y protección sostenibles de los recursos hídricos y marinos si va en detrimento del buen estado o del buen potencial ecológico de las masas de agua, incluidas las superficiales y subterráneas, y del buen estado ecológico de las aguas marinas;

4. se considera que una actividad causa un perjuicio significativo a la economía circular, incluidos la prevención y el reciclado de residuos, si genera importantes ineficiencias en el uso de materiales o en el uso directo o indirecto de recursos naturales; si da lugar a un aumento significativo de la generación, incineración o eliminación de residuos; o si la eliminación de residuos a largo plazo puede causar un perjuicio significativo y a largo plazo para el medio ambiente;

${ }^{109}$ Apartado 5.2 del Anexo I del Reglamento (UE) núm. 1303/2013. 
5. se considera que una actividad causa un perjuicio significativo a la prevención y el control de la contaminación cuando da lugar a un aumento significativo de las emisiones de contaminantes a la atmósfera, el agua o el suelo; y

6. se considera que una actividad causa un perjuicio significativo a la protección y restauración de la biodiversidad y los ecosistemas cuando va en gran medida en detrimento de las buenas condiciones y la resiliencia de los ecosistemas, o va en detrimento del estado de conservación de los hábitats y las especies, en particular de aquellos de interés para la Unión.

Además, en un afán tanto exhaustivo como didáctico, la UE ha concretado ${ }^{110}$ los caracteres ${ }^{111}$ que singularizan al principio $\mathrm{DNSH}$, a saber:

1․-- Carácter omnicomprensivo, pues debe aplicarse no solamente a las inversiones sino también a las reformas (Apartado 2.1 de la Guía técnica). Es algo coherente con la lógica del principio, que busca su plena eficacia, ya que en caso contrario las actividades e instalaciones previas pero objeto de reformas eludirían su cumplimiento a pesar de verse beneficiadas de unos fondos económicos destinados precisamente al objetivo climático.

$2^{\circ}$.- Carácter integral, pues la medida debe apoyarse en un objetivo ambiental de los del Reglamento de taxonomía, que debe ser identificado, pero, y esto es lo importante, corresponde quedar acreditado que no se causa un perjuicio significativo a los objetivos ambientales restantes (Apartado 2.2 de la Guía técnica). Es decir, la ausencia de perjuicio significativo ha de ser respecto de todos y cada uno de esos objetivos.

3‥- Carácter sustancial, ya que no es necesario que el cumplimiento sea total sino que es suficiente que la medida contribuya sustancialmente al menos a uno de los seis objetivos ambientales del Reglamento de taxonomía para considerar que se cumple con el principio DNSH en relación con el objetivo (Apartado 2.2 de la Guía técnica). Como contribución sustancial el Reglamento de taxonomía determina unos parámetros diferentes según cada uno de esos

\footnotetext{
${ }^{110}$ A través de la Comunicación de la Comisión 2021/C58/01, ya mencionada.

${ }^{111}$ La Guía técnica habla de "principios rectores", pero consideramos una inconsistencia referirse a principios del principio DNSH. Consideramos más correcto hablar de caracteres por cuanto son las notas que lo singularizan.
} 
objetivos (art. 10 a 16). En lo que ahora nos interesa, se valora, por ejemplo, el refuerzo de los sumideros de carbono, en particular mediante la prevención de la deforestación y de la degradación de los bosques, la recuperación de los bosques, la gestión sostenible y la recuperación de las tierras agrícolas, los pastizales y los humedales, la forestación y la agricultura regenerativa (art. 10.1.f)) o una gestión forestal sostenible, con unas prácticas y una utilización de los bosques y de los terrenos forestales que contribuyan a mejorar la biodiversidad o que frenen o eviten la degradación de los ecosistemas, la deforestación y la pérdida de hábitats (art. 15.1.d)). En definitiva, en virtud de este carácter, el principio DNSH quedaría verificado si se prueba la ausencia de un perjuicio significativo a los otros cinco objetivos ambientales.

$4^{\circ}$-- Carácter independiente. El cumplimiento del Derecho Ambiental vigente nacional y europeo es una obligación independiente de la realización del principio DNSH, y, por ello, esa adecuación legal no suspende la necesidad de una evaluación según este principio (Apartado 2.3 de la Guía técnica). Aunque el cumplimiento de la legislación ambiental sea un indicio muy sólido de que la medida no causa un perjuicio ambiental, ello "no conlleva automáticamente su conformidad con el principio DNSH, en particular debido a que algunos de los objetivos que engloba el art. 17 no se han reflejado todavía por completo en la legislación medioambiental de la UE'. Es decir, este principio es un plus, un nivel superior y adicional al diseñado en la normativa ambiental, que es el mínimo de obligado cumplimiento. Precisamente por tratarse de un grado de exigencia suplementario debe ser objeto del debido reconocimiento legal.

Por ello, las evaluaciones de impacto ambiental o las pruebas de sostenibilidad deben tenerse en cuenta en la evaluación con arreglo al principio DNSH. Permiten configurar una presunción iuris tantum a favor del cumplimiento del principio, pues si bien no implican de forma automática que no haya perjuicio significativo alguno, constituyen un claro indicio de ausencia del mismo en relación con varios de los objetivos ambientales tantas veces citados. De hecho, y en el caso concreto del sector forestal, la Guía técnica reconoce que una evaluación de impacto ambiental puede "(...) ser prueba suficiente para que el Estado miembro demuestre el cumplimiento del principio DNSH en lo relativo a ciertos objetivos medioambientales pertinentes (...), así como la 
protección y recuperación de la biodiversidad y de los ecosistemas. Sin embargo, ello no exime al Estado miembro de someter esa medida a una evaluación según el principio DNSH, puesto que una evaluación de impacto ambiental, una EEM o una verificación no abarcan todos los aspectos necesarios que forman parte de una evaluación según el principio DNSH", ya que las obligaciones previstas para las evaluaciones de impacto ambiental ni sus enfoques coinciden con lo prevenido en el art. 17 del Reglamento de taxonomía. Y, a la inversa, la evaluación del principio DNSH no exime de la obligación de realizar, por ejemplo, una evaluación de impacto ambiental o de las evaluaciones adicionales si la operación se ubica en zonas sensibles para la biodiversidad o en su área de influencia ${ }^{112}$.

5․- Carácter vitalicio, pues exige tener en cuenta su impacto ambiental a lo largo de todo su ciclo de vida útil, enfoque derivado del art. 17 del Reglamento de taxonomía. Más concretamente, se deben evaluar según el principio DNSH tanto los impactos directos e indirectos primarios de la medida, siendo los primeros los que se producen en el momento de su aplicación, y los segundos los que se causan fuera de esos proyectos y pueden materializarse tras su aplicación, pero que son razonablemente previsibles y pertinentes (Apartado 2.4 de la Guía técnica).

6‥- Carácter de ausencia de intervención. Se trata de determinar el término de comparación que debe tenerse en cuenta para evaluar si se va a causar un perjuicio significativo. Por eso, y en una clara manifestación del principio proambiente, este carácter consiste en valorar el impacto ambiental de la medida en comparación con una situación sin impacto ambiental negativo, es decir, sin referencia a otra actividad existente o prevista. También se entiende derivado del preceptivo enfoque del Medio Ambiente a través de una perspectiva absoluta y no relativa, respaldado además por el principio de precaución (Apartado 2.4 de la Guía técnica).

$7^{\circ}$.- Carácter finalista, consistente en garantizar el cumplimiento del principio DNSH a nivel de hitos y metas, incluidos los procesos de licitación y

\footnotetext{
${ }^{112}$ De conformidad con las Directivas 2009/147/CE, del Parlamento Europeo y del Consejo, de 30 de noviembre de 2009, relativa a la conservación de las aves silvestres, y 92/43/CEE, del Consejo, de 21 de mayo de 1992, relativa a la conservación de los hábitats naturales y de la fauna y flora silvestres (Apartado 2.3 de la Guía técnica).
} 
adjudicación de los contratos del sector público (Apartado 2.4 de la Guía técnica) $)^{113}$.

8‥- Carácter técnico. Cuando se evalúa el cumplimiento del principio DNSH, los Estados miembros tienen la opción de basarse en los criterios técnicos de selección en los actos delegados en virtud del Reglamento del MRR (Apartado 2.5 de la Guía técnica).

\section{2.- Desarrollo del principio de restauración.}

Hasta la fecha, la normativa ambiental se centraba especialmente en el elemento de conservación: era preciso proteger las especies, los hábitats, incluidos los urbanos, y los elementos naturales que nos rodean (aguas, atmósfera, suelo ...) a fin de evitar su desaparición, extinción o degradación. Nos conformábamos con preservar lo que se tenía, lo que habíamos heredado de nuestros ancestros, ambientalmente hablando. Después de décadas instalados en este enfoque, se está produciendo una positiva evolución al ponerse el acento en conseguir revertir los perjuicios causados al Medio Ambiente, es decir, trabajar en su restauración.

Indudablemente este principio no es novedoso pues fue perfectamente entendido por el constituyente español al recogerlo de modo expreso en el art. 45.2 (CE) como una de las obligaciones de todos los poderes públicos, inspirado sin duda por el Principio 3 de la Conferencia de Estocolmo de $1972^{114}$, entonces la fuente de Derecho Ambiental internacional de referencia. Pero lo cierto es que a pesar de contemplarse en el texto constitucional apenas ha sido objeto de atención legislativa que lo desarrolle: no hay duda de que ha sido un principio que políticamente nunca ha interesado pues carece de atractivo electoral, amén de necesitar de un importante esfuerzo económico por parte de las Administraciones públicas. No obstante, es de justicia reconocer que en el ámbito forestal el principio de restauración ha estado muy presente desde sus inicios. Así, sin realizar una exhaustiva retrospectiva histórica, en la Ley de Montes de 8 de junio de 1957 (en adelante, LM-57) se reservaba el

\footnotetext{
${ }^{113}$ Estos hitos y metas están sujetos al art. 19.bis del Reglamento del MRR.

${ }_{114}$ Principio 3: "Debe mantenerse y, siempre que sea posible, restaurarse o mejorarse la capacidad de la tierra para producir recursos vitales renovables".
} 
Título III exclusivamente a regular la repoblación forestal, y el Capítulo $1^{\circ}$ del Título IV a los proyectos de regulación hidrológico-forestal, los cuales se ejecutaban bajo el expreso gobierno del principio de restauración (art. 57.1) ${ }^{115}$. Del mismo modo el Título I del Libro III del Reglamento de Montes, aprobado por Decreto 485/1962, de 22 de febrero, sobre repoblación forestal, así como su Título III sobre proyectos de restauración hidrológico-forestal ${ }^{116}$. De aquí pasó a la vigente LM, siendo su principal ejemplo el Capítulo II de su Título IV con un rótulo de ilustrativa redacción: "Conservación de suelos, lucha contra la erosión y la desertificación y restauración hidrológico-forestal". Consecuentemente, y como no podía ser de otro modo, el Plan nacional de actuaciones prioritarias en materia de restauración hidrológico-forestal, control de la erosión y defensa contra la desertificación, propone varias actuaciones, entre las que destacamos los trabajos de restauración, conservación y mejora de la cubierta vegetal, la repoblación forestal, y la reforestación de tierras agrarias.

La ONU siempre ha tenido presente, al menos nominalmente, este principio desde 1972. Así, en su Resolución 66/288, como documento final de la Conferencia sobre Desarrollo Sostenible celebrada en Río de Janeiro en 2012, ya se puso de relieve la importancia de la restauración de los ecosistemas para lograr dicho desarrollo sostenible. Por ello, precisamente en virtud de los ODS de la Agenda 2030 anteriormente citados, la ONU ha declarado la "Década para la Restauración de los Ecosistemas” a 2021-2030, “(...) a fin de apoyar y ampliar los esfuerzos encaminados a prevenir, detener e invertir la degradación de los ecosistemas en todo el mundo y concienciar sobre la importancia del éxito de la restauración de los ecosistemas"117. Aunque incurre en un cierto voluntarismo, inequívocamente determina que el principio de restauración ${ }^{118}$ deviene imprescindible para una correcta inteligencia y gestión del Medio

115 "El Servicio Hidrológico-forestal tendrá a su cargo el estudio, formación y ejecución de proyectos de regulación hidrológico-forestal y restauración de montañas, conservación de suelos forestales, corrección de torrentes y ramblas, contención de aludes, fijación de dunas y suelos inestables, con el fin de regularizar el régimen de las aguas y atender a la defensa de pantanos, vías de comunicación, poblados o cualesquiera otras análogas".

${ }_{116}$ Art. 341.1 (Reglamento de Montes, aprobado por Decreto 485/1962, de 22 de febrero), cuyo texto es una mera correlación del ya reproducido art. 57.1 (LM-57).

${ }_{117}$ Parte dispositiva Segunda de la ya citada Resolución 73/284 de la Asamblea General de la ONU.

118 JAQUENOD DE SZöGöN (1991: 371 a 381) lo incluye junto al mejoramiento dentro del más amplio de regulación jurídica integral, pues lo cataloga unido a la prevención y represión, defensa y conservación. 
Ambiente. Incluso se ha hablado de "una necesidad urgente de enfoques adaptativos de restauración forestal' a nivel europeo ${ }^{119}$, lo que es indicativo de su actual relevancia.

Como resultado paradigmático de la actual trascendencia de este principio tenemos, por un lado, el propio Acuerdo de París de 2015, al reconocer la importancia de aumentar los sumideros, operación que sólo cabe a través de la restauración ${ }^{120}$. Por otro, el Pacto Verde Europeo de 2019, al recoger el mandato de que "La superficie forestal de la UE debe mejorarse, tanto en calidad como en cantidad, para que la UE alcance la neutralidad climática y un medio ambiente sano. La forestación y reforestación sostenibles y la recuperación de bosques degradados pueden incrementar la absorción de CO2, a la vez que mejoran la resiliencia de los bosques (...)" (Apartado 2.1.7). Además, la Nueva Estrategia Forestal de la UE para 2030 reconoce el aumento de la superficie forestal europea gracias a la restauración activa, por lo que propone garantizarla (Apartado 3.2). Y, por último, el novedoso Real Decreto 690/2021, de 3 de agosto, por el que se regula el Fondo de Restauración Ecológica y Resiliencia, como consecuencia de las previsiones de la actual redacción del art. 78 de la Ley 42/2007, de 13 de diciembre, del Patrimonio Natural y de la Biodiversidad, dada por el Real Decreto-Ley 36/2020, de 30 de diciembre, ya citado. Se trata de un fondo (en adelante, FRER) carente de personalidad jurídica propia, y con la finalidad de desarrollar aquellas medidas destinadas a apoyar la consecución de los objetivos del Plan de Recuperación, Transformación y Resiliencia ${ }^{121}$, entre los que se encuentran el cambio climático y su mitigación, así como la protección del patrimonio natural, de la biodiversidad y de los bosques ${ }^{122}$.

Pero quizás lo más interesante sea la tipología de las operaciones por las que se instrumentalizan dichas medidas: subvenciones, contratos conforme la normativa de contratación del sector público, convenios con sujetos de Derecho

\footnotetext{
${ }^{119}$ Nueva Estrategia Forestal de la UE para 2030, aprobada por la Comunicación de la Comisión al Parlamento Europeo, al Consejo, al Consejo Económico y Social Europeo y al Comité de las Regiones Vacías (COM (2021) 572 final) de 16 de julio de 2021.

${ }^{120}$ De hecho, la ONU, a través de su Resolución 73/284, ya calendada, reconoció que “(...) el secuestro de carbono debido a la restauración de los ecosistemas es importante y hace una contribución adicional al logro del objetivo a largo plazo referente a la temperatura del Acuerdo de París".

121 Art. 1.2 (Real Decreto 690/2021).

122 Apartado c) y e) del art. 4.1 (Real Decreto 690/2021).
} 
público y privado, encargos a medios propios personificados y encomiendas de gestión ${ }^{123}$. Todos ellos son institutos jurídicos que encajan perfectamente dentro de las contraprestaciones del contrato territorial ${ }^{124}$, por lo que éste es sin duda la figura por la que, sin nombrarla explícitamente, se está apostando para articular las ayudas a cargo del FRER.

En coherencia con la urgencia que se predica de la aplicación de este principio al ámbito forestal, está anunciado que la Comisión europea propondrá un instrumento jurídicamente vinculante para la restauración de los ecosistemas, que abarque en particular los de mayor potencial para capturar y almacenar carbono y para prevenir y reducir el impacto de las catástrofes naturales ${ }^{125}$. Ello supondrá un verdadero revulsivo e impulso normativo a este principio que, incluso, prevé el aumento de profesionales específicos, de "expertos en prácticas mejoradas de ordenación forestal sostenible, incluida la reforestación y restauración adaptativas" (Apartado 2.4).

\section{3.- Impulso a la gestión forestal sostenible.}

La gestión forestal sostenible se integra en nuestro ordenamiento jurídico nacional especialmente a partir de la LM, al aparecer como el primero de los principios que la inspiran (art. 3.a)), y se define como "la organización, administración y uso de los montes de forma e intensidad que permita mantener su biodiversidad, productividad, vitalidad, potencialidad y capacidad de regeneración, para atender, ahora y en el futuro, las funciones ecológicas, económicas y sociales relevantes en el ámbito local, nacional y global, y sin producir daños a otros ecosistemas" (art. 6.e) LM) ${ }^{126}$. De hecho, no sólo es un principio de la ley que, al fin y al cabo, únicamente implica ser un criterio de actuación e interpretación, sino que constituye un auténtico mandato a todos los agentes que intervienen en el sector forestal, en virtud del tenor literal del

\footnotetext{
123 Art. 5 (Real Decreto 690/2021).

124 GARCÍA ASENSIO (2020: 10).

${ }^{125}$ Nueva Estrategia Forestal de la UE para 2030, Apartado 3.2.

${ }^{126}$ En términos más actuales y concretos, la Nueva Estrategia Forestal de la UE para 2030 considera que por ordenación sostenible de los bosques ha de entenderse la administración y el uso de las tierras forestales de una manera, y a un ritmo, que mantenga su diversidad biológica, productividad, capacidad de regeneración, vitalidad y su potencial para cumplir, ahora y en el futuro, las funciones ecológicas, económicas y sociales pertinentes, a nivel local, nacional y mundial, y que no cause daños a otros ecosistemas.
} 
art. 32.1 (LM), cuando prescribe que "Los montes deben ser gestionados de forma sostenible, integrando los aspectos ambientales con las actividades económicas, sociales y culturales, con la finalidad de conservar el medio natural al tiempo que generar empleo y colaborar al aumento de la calidad de vida y expectativas de desarrollo de la población rural'.

Este impulso resulta conforme con la finalidad de la gestión forestal sostenible, que tal y como hemos señalado en anteriores ocasiones ${ }^{127}$, va más allá de una mera conservación, mejora, aprovechamiento o regeneración del monte, típico objeto de la silvicultura ${ }^{128}$, sino que incorpora actuaciones informadas de valores ambientales y sociales de relevancia. No obstante, ello no significa que deba excluirse $o$ abandonarse los instrumentos de acción de la silvicultura tradicional, pues como ilustrativamente nos muestra el Programa de Acción Nacional de lucha contra la Desertificación se vincula la gestión forestal sostenible con la repoblación forestal y demás tratamientos silvícolas (Medidas 1.3), del mismo modo que la ya referenciada Resolución de la Asamblea General de la ONU 73/284, en su parte expositiva, al incluir la forestación y la reforestación dentro de la gestión forestal sostenible.

Ya desde 2003 la gestión forestal sostenible ha estado orientada hacia el cambio climático, como lo acredita la Disposición Adicional Séptima (LM), al ordenar no sólo la elaboración de un estudio sobre las necesidades de adaptación del territorio forestal español al cambio climático, sino que deben analizarse "los métodos de ordenación y tratamientos silvícolas más adecuados para dicha adaptación", es decir y, en definitiva, el contenido de los instrumentos operativos de gestión forestal sostenible a utilizar. Estamos, pues, ante lo que ha venido en denominarse como silvicultura del carbono ${ }^{129}$.

A pesar de estas previsiones legales, en estos últimos tiempos la gestión forestal sostenible está siendo objeto de un estímulo significativo en el plano normativo. A modo de ejemplo, la ya citada Disposición Adicional $3^{\underline{a}}$ (LMG) dispone que se promuevan medidas de gestión forestal y de silvicultura encaminadas a la adaptación, resiliencia y resistencia de los montes a los

\footnotetext{
${ }^{127}$ GARCÍA ASENSIO (2018.b: 338-339).

128 Apartado d) del art. 6 (LM).

${ }^{129}$ RODRÍGUEZ-CHAVES MIMBRERO (2018: 642).
} 
cambios futuros de las variables meteorológicas, mediante, entre otras, el fomento de repoblaciones y la restauración con especies arbóreas y arbustivas adecuadas (apartado c)). De similar forma, aunque más extenso, el art. 18 (Ley 16/2017) para Cataluña.

La última de estas novedades la encontramos en la LCC cuando prescribe, aunque sólo sea como mera posibilidad, que en las licitaciones de redacción de proyectos, de contratos de obra o concesión de obra se podrán incluir, como prescripciones técnicas, alguna de los siguientes: (i) que la madera que se utilice en las construcciones proceda de bosques gestionados de forma sostenible y atendiendo a su huella ecológica; y (ii) actuaciones de repoblación forestal con especies autóctonas, como medida compensatoria para paliar la huella de carbono resultante de la ejecución de la obra o servicio objeto de licitación (art. 31.3 LCC). La primera de estas medidas nos remite directamente a la madera procedente de montes acreditados, lo que implica exigir en la licitación una de las certificaciones reconocidas, como FSC y PEFC ${ }^{130}$. La segunda, aunque sólo tenga un carácter potestativo, es interesante al contemplar, primero, la repoblación forestal, es decir tanto la reforestación como la forestación, sin hacer distinciones entre ambas. En segundo lugar, contempla que esas actuaciones forestales lo sean exclusivamente con especies autóctonas, lo que conlleva el estudio correspondiente. En puridad esta previsión no sólo hace referencia a una especie forestal a nivel de especie, sino que debe entenderse también genéricamente, por lo que sólo podrían usarse materiales forestales de reproducción de las especies forestales de la misma región de procedencia ${ }^{131}$. En caso de no hacerse de este modo no se estaría cumpliendo con la finalidad de prevalencia de lo nativo que persigue el legislador. Por último, al configurarse como una medida compensatoria de la huella de carbono de la ejecución de la obra o servicio licitados, deberá justificarse debidamente que se cumple con esta equivalencia en cada caso.

\footnotetext{
${ }^{130}$ GARCÍA ASENSIO (2018.b: 339 a 341).

${ }^{131}$ Art. 2 del Real Decreto 289/2003, de 7 de marzo, sobre comercialización de los materiales forestales de reproducción.
} 


\section{4.- La gestión forestal sostenible como un instrumento de lucha contra la pérdida de biodiversidad.}

Consecuentemente con lo que se acaba de exponer, algo parecido le ha sucedido al uso de la gestión forestal sostenible como instrumento para evitar la pérdida de la biodiversidad. La conservación y restauración de ésta se configura como un principio inspirador de la LM, conforme su art. 3.f), y, quizás más emblemático, se reconoce que los montes son un depósito de diversidad biológica, lo que les dota, entre otros motivos, de una relevante función social (art. 4 LM).

A nivel europeo la gestión forestal sostenible debe tener en cuenta los criterios de biodiversidad del monte ${ }^{132}$. Lo que se ha materializado recientemente en la Nueva Estrategia Forestal de la UE para 2030, al promover no sólo la protección de los bosques primarios y antiguos de la UE (Apartado 3.1) sino la repoblación forestal de bosques biodiversos (Apartado 3.3). Este enfoque encierra un importante cambio en la gestión forestal, por cuanto fija que no toda repoblación forestal es legítima, sino que ha de cumplir con los requisitos de ser activa y sostenible, no siendo ya una decisión voluntaria del silvicultor. Como consecuencia, la Comisión europea se ha comprometido a desarrollar directrices sobre forestación y reforestación amigables con la biodiversidad para el año 2022 (Apartado 3.4).

\section{V.- CONCLUSIONES}

La actual política forestal en todo el mundo viene condicionada a la lucha contra el cambio climático, tanto a nivel global, europeo, nacional y autonómico, con una importante imbricación con el bien jurídico de la salud humana y su protección. Hasta tal punto que no sólo el aumento de la superficie forestal beneficia la salud sino que la atención médica reduce la deforestación. La condición de los montes como sumideros de dióxido de carbono le dota, a estos efectos, de una importante trascendencia que la normativa nacional y europea, con apoyo en el Acuerdo de París, la Agenda 2030, el Pacto Verde

\footnotetext{
${ }^{132}$ Dictamen CESE NAT/412 sobre "El papel de los bosques y el sector forestal en el cumplimiento de los compromisos de la UE en la lucha contra el cambio climático" de 25 de marzo de 2009, Ponente: Seppo Kallio, Apartado 5.6 in fine.
} 
Europeo y el Reglamento (UE) 2021/1119, recogen recientemente, aún más cuando se enmarca dentro de las soluciones basadas en la Naturaleza, más adecuadas para combatir el cambio climático. Esto ha provocado un redimensionamiento de los elementos que la integran y de sus instrumentos tradicionales (repoblación forestal, reforestación, forestación, gestión forestal, etc). Así, la repoblación forestal se orienta no tanto a satisfacer intereses productivistas sino a mantener las masas boscosas, fomentarlas, y a restaurar las perdidas, todo en aras de lograr un óptimo climático.

La condición de nuestros terrenos forestales como sumideros de dióxido de carbono ha obligado, no sólo a impulsar medidas de fomento, tales como su aumento, el uso de prácticas de gestión forestal sostenible y la participación de personas y entidades propietarias y gestoras, sino a darle a los montes un novedoso tratamiento jurídico, quizás todavía necesitado de más recorrido, especialmente en lo referente a permitir que la silvicultura del carbono permita obtener rendimientos por sí misma, que se reconoce necesario pero que no se crea el marco jurídico preciso, no sirviendo actualmente la huella de carbono a estos efectos. Por eso la Ley 7/2021 ha supuesto una oportunidad perdida, pues, por un lado, su marcada generalidad le ha impedido descender del nivel de las declaraciones de principios $y$, por otro, ha obviado adoptar medidas prácticas como dotarle de mayores contenidos a la huella de carbono como instrumento de mercado.

Dentro del citado redimensionamiento destacamos la incorporación de un nuevo principio ("no causar un perjuicio significativo"), de clara configuración horizontal, y que goza de la seguridad jurídica que supone la positivización de los supuestos de "perjuicio significativo". Su carácter independiente le permite actuar en un nivel superior al del mero cumplimiento de la normativa ambiental.

Precisamente uno de los puntos que más impulso está recibiendo es el desarrollo del principio de restauración, especialmente desde la propia ONU, paso lógico en nuestra normativa por cuanto en las últimas décadas se ha puesto el acento en la conservación y preservación de las masas forestales, debiendo ahora imponerse el objetivo de aumentar los sumideros recuperando el terreno forestal desaparecido. 
Por último, la gestión forestal sostenible, como instrumento de administración del monte, y de lucha contra la pérdida de la biodiversidad, completa las líneas que definen ese redimensionamiento de las políticas forestales actuales.

\section{BIBLIOGRAFÍA}

AGUIRRE I FONT, Josep M. "La resiliencia del territorio al cambio climático: retos y herramientas jurídicas desde el planteamiento urbanístico". Revista Catalana de Dret Ambiental Vol. X núm. 2 (2019), 46 pp.

ARAUZ, Cristina y MARZO, Mariano. "Las soluciones basadas en la Naturaleza como herramienta para mitigar el cambio climático". Rev. Ambienta núm. 127 (2021): 24-31.

DESANKER, Paul V. "El Protocolo de Kyoto y el MDL en África: buena idea, pero ...". Rev. Unasylva núm. 222 (2005): 24-26.

ESPINEL GONZÁLEZ, María Almudena y ORTEGA SÁNCHEZ, Mercedes. "UAS: ¿nuevos recursos para el Medio Ambiente?", en vol. col. Lorenzo Mateo Bujosa Vadell y Federico Bueno de Mata (dirs.). "Daños ambientales y tecnologías digitales. Los drones en la investigación y enjuiciamiento de delitos de incendio". Ed. Tirant lo Blanch. Valencia. 2021, pág. 165-197.

GARCÍA ASENSIO, José Miguel. "Análisis jurídico de los aprovechamientos forestales en España". Ed. Atelier. Barcelona. 2017. 744 pp.

GARCÍA ASENSIO, José Miguel. "Régimen jurídico de la captura y almacenamiento de carbono atmosférico por los montes. Propuesta de creación de un instrumento económico de mercado". Revista Aragonesa de Administración Pública núm. 51 (2018.a): 109-174.

GARCÍA ASENSIO, José Miguel. "Aproximación jurídica a los instrumentos económicos de mercado en el sector forestal', en vol. col. Gerardo GarcíaÁlvarez (dir.). "Mecanismos económicos y de mercado para la protección ambiental'. Monografías de la Revista Aragonesa de Administración Pública XIX (2018.b): 329-377. 
GARCÍA ASENSIO, José Miguel. "El contrato territorial en España aplicado al sector forestal'. Revista Aranzadi de Derecho Ambiental núm. 47 (2020): 127179.

GARCÍA LOZANO, Luis Miguel. "La noción de bosque en la regulación española. Ante el intento de búsqueda de un concepto jurídico". Revista Digital de Derecho Administrativo núm. 26 (2021): 229-261.

GARCÍA MARTINO, Francisco. "Consideraciones generales sobre la historia y la literatura de la ciencia forestal en Alemania (II)". RFEA (1868) Tomo I: 514537.

GUAITA, Aurelio. "Derecho Administrativo. Aguas, montes, minas". 2ª edición. Ed. Cívitas. Madrid. 1986, 400 pp.

JAQUENOD DE SZöGöN, Silvia. "El Derecho Ambiental y sus principios rectores". Ed. Dykinson. Madrid. 1991. 525 pp.

LÓPEZ RAMÓN, Fernando. "Principios de Derecho Forestal". Ed. Aranzadi. Cizur Menor. 2002. 146 pp.

LÓPEZ RAMÓN, Fernando. "Introducción general: regresiones del Derecho ambiental", en vol. col. Fernando López Ramón (coord.). "Observatorio de Políticas Ambientales 2011”. Ed. Aranzadi. Cizur Menor. 2011, pág. 19-24.

LÓPEZ RAMÓN, Fernando. "Notas de la Ley de Cambio Climático". Actualidad Jurídica Ambiental núm. 114 (2021). 22 pp.

LOZANO CUTANDA, Blanca y RÁBADE BLANCO, José María. "El pago por servicios ambientales para el desarrollo sostenible del medio rural: los contratos territoriales", en vol. col. F.J. Sanz Larruga, Marta García Pérez y J.J. Permás García (dirs.). "Libre mercado y protección ambiental. Intervención y orientación ambiental de las actividades económicas". Ed. INAP. Madrid. 2013, pág. 337-357.

MASA ORTIZ, Miguel. "Legislación de Montes. Comentarios al Reglamento de 22 de febrero de 1962". Ed. Nauta. Barcelona. 1964. 892 pp.

MEDINA, Alvin Leroy. "An english-spanish glossary of terminology used in forestry, range, wildlife, fishery, soils, and botany". Ed. United States Department of Agriculture Forest Service. Rocky Mountain Forest and Range 
Experiment Station. Fort Collins. 1988. 54 pp., disponible en https://www.fs.fed.us/rm/pubs rm/rm gtr152.pdf.

MINISTERIO DE AGRICULTURA Y PESCA, ALIMENTACIÓN Y MEDIO AMBIENTE Y OFICINA ESPAÑOLA DE CAMBIO CLIMÁTICO (OECC) (enero de 2018). Información sobre la sección de proyectos de absorción de dióxico de carbono. Obtenido de Versión 5: http://www.magrama.gob.es/es/cambioclimatico/temas/mitigacion-politicas-y-medidas/documentoapoyopa_tcm7330264.pdf.

OYARZUN LARRAYOZ, Francisco. "La política forestal y su evolución". Rev. Montes núm. 196 (1974): 13-24.

PAHISSA ESPLUGA, Marta. "La naturaleza como activo para la salud". Rev. Ambienta núm. 127 (2021): 76-87.

PIZARRO NEVADO, Rafael. "Conservación y mejora de terrenos forestales. Régimen jurídico de las repoblaciones”. Ed. Lex Nova. Valladolid. 2000. 491 pp. REAL ACADEMIA ESPAÑOLA (RAE). "Diccionario de la lengua española". 2 tomos. 21를 edición. Ed. Espasa Calpe. Madrid. 1992. 2133 pp.

RODRÍGUEZ ÁLVAREZ, D. "El sector forestal y los mercados de carbono". $7^{\circ}$ Congreso Forestal Español (2017). 12 pp.

RODRÍGUEZ-CHAVES MIMBRERO, Blanca. "COP 21: nuevas perspectivas para los montes por su función mitigadora ante el cambio climático". RDUyMA núm. 311 (2017): 411-430.

RODRÍGUEZ-CHAVES MIMBRERO, Blanca. "La regulación climática en el medio natural: absorción y compensación CO2 en el sector UTCUTS y el singular potencial de los montes", en vol. col. Susana Galera y Mar Gómez (eds.), "Políticas locales de clima y energía: teoría y práctica", Ed. INAP. Madrid. 2018, pág. 621 a 646.

SARASÍBAR IRIARTE, Miren. "El Derecho Forestal ante el Cambio Climático: las funciones ambientales de los bosques". Ed. Aranzadi. Cizur Menor. 2007. $301 \mathrm{pp}$.

SORO MATEO, Blanca. "Un Derecho para el cambio climático". REDA núm. 209 (2020): 279-316. 
VIEITES, David R. y HERRANDO-PÉREZ, Salvador. "Facilitar atención médica reduce la deforestación". Rev. Quercus núm. 422 (2021): 54-56. 